\title{
RNA binding protein 24 regulates the translation and replication of hepatitis $\mathrm{C}$ virus
}

\author{
Huang $\mathrm{Cao}^{1,2}$, Kaitao Zhao ${ }^{1,2}$, Yongxuan Yao, ${ }^{1,2}$, Jing Guo ${ }^{1,2}$, Xiaoxiao Gao ${ }^{1,2}$, Qi Yang ${ }^{1,2}$, Min Guo ${ }^{1,2}$, \\ Wandi Zhu', Yun Wang ${ }^{1}$, Chunchen $\mathrm{Wu}^{1}$, Jizheng Chen ${ }^{1}$, Yuan Zhou', Xue Hu${ }^{1}$, \\ Mengji Lu ${ }^{3}$, Xinwen Chen ${ }^{1 \bowtie}$, Rongjuan Pei ${ }^{1 \bowtie}$ \\ 1 State Key Laboratory of Virology, Wuhan Institute of Virology, Chinese Academy of Sciences, Wuhan 430071, China \\ 2 University of Chinese Academy of Sciences, Beijing 100049, China \\ ${ }^{3}$ Department of Infectious Disease, University Hospital Essen, University of Duisburg-Essen, Gebäude V15, 45117 Essen, \\ Germany \\ \Correspondence: chenxw@wh.iov.cn (X. Chen), rongjuan_pei@wh.iov.cn (R. Pei) \\ Received October 24, 2017 Accepted December 10, 2017
}

\begin{abstract}
The secondary structures of hepatitis C virus (HCV) RNA and the cellular proteins that bind to them are important for modulating both translation and RNA replication. However, the sets of RNA-binding proteins involved in the regulation of $\mathrm{HCV}$ translation, replication and encapsidation remain unknown. Here, we identified RNA binding motif protein 24 (RBM24) as a host factor participated in HCV translation and replication. Knockdown of RBM24 reduced HCV propagation in Huh7.5.1 cells. An enhanced translation and delayed RNA synthesis during the early phase of infection was observed in RBM24 silencing cells. However, both overexpression of RBM24 and recombinant human RBM24 protein suppressed HCV IRES-mediated translation. Further analysis revealed that the assembly of the $80 \mathrm{~S}$ ribosome on the HCV IRES was interrupted by RBM24 protein through binding to the $5^{\prime}$-UTR. RBM24 could also interact with HCV Core and enhance the interaction of Core and $5^{\prime}$-UTR, which suppresses the expression of HCV. Moreover, RBM24 enhanced the interaction between the 5'- and $3^{\prime}$-UTRs in the HCV genome, which probably explained its requirement in $\mathrm{HCV}$ genome replication. Therefore, RBM24 is a novel host factor involved in HCV replication and may function at the switch from translation to replication.
\end{abstract}

KEYWORDS RNA binding protein, RBM24, hepatitis C virus, translation, replication

\section{INTRODUCTION}

The genome of hepatitis $\mathrm{C}$ virus (HCV) is composed of a single open reading frame (ORF) flanked by $5^{\prime}$ - and 3 'untranslated regions (UTRs). The ORF encodes a polyprotein of approximately 3,000 amino acids (aa) that is processed into viral structural and non-structural proteins by host and viral proteinases. Like other positive-strand RNA viruses, the genomic RNA of HCV is believed to serve as the template for translation and negative-strand RNA synthesis (Ranjith-Kumar and Kao, 2006). The same RNA cannot serve as template for both processes simultaneously because translation proceeds in the $5^{\prime}$ to $3^{\prime}$ direction, whereas negative-strand RNA synthesis occurs in the $3^{\prime}$ to $5^{\prime}$ direction (Shi and Lai, 2006). Thus the control of translation and replication during the initial period post-infection is essential for viral proliferation.

The $5^{\prime}$ - and 3'-UTRs are the most conserved regions of HCV RNA among the different genotypes and isolates. Both of these regions form complex secondary structures with multiple stem-loops and are involved in the control of translation and RNA replication (Shi and Lai, 2006). The 5'UTR where the internal ribosome entry site (IRES) located within is the key element that mediates HCV translation initiation (Tsukiyama-Kohara et al., 1992). During ribosome complex recruitment, the core domain of IRES (domains II to IV of the $5^{\prime}$-UTR) directly binds the $40 \mathrm{~S}$ subunit. Domain III interacts with $18 \mathrm{~S}$ rRNA and subunits of elF3 (Malygin et al., 2013; Sun et al., 2013), while domain II facilitates recruitment of the $60 \mathrm{~S}$ ribosome and promotes translation elongation (Filbin et al., 2013; Locker et al., 2007). Besides functioning 
in translation, domains I and II of the $5^{\prime}$-UTR, corresponding with the most 3 '-terminal region of the negative strand, are necessary for HCV replication (Kim et al., 2002; Schuster et al., 2002; Mahias et al., 2010; Reigadas et al., 2001; Astier-Gin et al., 2005). The 3'-UTR composed of a variable region, a polyU/UC tract of variable length and a highly conserved 98-bases element designated as $3^{\prime}-\mathrm{X}$, is an essential cis-acting element for HCV replication, while the $3^{\prime}$ $X$ region is also involved in IRES dependent translation (Bai et al., 2013; Wood et al., 2001; Shetty et al., 2010). Another cis-acting element functioning in both replication and translation is the stem-loop 3.2 (SL3.2) located at the $3^{\prime}$ end of the NS5B coding region (Cheng et al., 1999). The interaction between SL3.2 and $3^{\prime}-X$ is necessary for replication (Friebe et al., 2005), while the interaction between SL3.2 and domain III of the $5^{\prime}$-UTR has been reported to inhibit IRESmediated translation (Romero-Lopez and Berzal-Herranz, 2012,2009 ), which is thought to play a crucial role in the switch between the translation and replication during the $\mathrm{HCV}$ life cycle.

In addition to the cis elements, the translation and replication of $\mathrm{HCV}$ is under the control of trans-acting factors, including viral and host factors. The nonstructural proteins form replication complex and control the RNA replication, while the Core, NS3 has also been reported to modulate IRES activity in trans (Shimoike et al., 1999; Ray and Das, 2011; Li et al., 2003; Shimoike et al., 2006; Tanaka et al., 2000). Among the host factors controlling HCV replication or translation in trans, several candidates are involved in mediating both of these processes, including human La protein, poly( $\mathrm{rC}$ )-binding protein 2 (PCBP2) and mice minute virus NS1-associated protein 1 (NSAP1) (Ali et al., 2000; Ito and Lai, 1997; Chang and Luo, 2006; Spangberg and Schwartz, 1999; Park et al., 2011). La protein has been reported to enhance HCV IRES-mediated translation by binding to the $5^{\prime}$-UTR of the HCV genome (Ali et al., 2000). Its involvement in HCV replication may be explained by the fact that it also interacts with the 3'-UTR of HCV RNA and prevents its degradation, in addition to promoting the linkage between the 5'-UTR and 3'-UTR (Kumar et al., 2013). The interplay of La protein and NS3, a viral trans-element, may regulate the translation-replication switch of $\mathrm{HCV}$ (Ray and Das, 2011). PCBP2 interacts with the 5'- and $3^{\prime}$-UTRs of HCV RNA and enhances HCV translation, the circularization of HCV RNA and replication (Wang et al., 2011). NSAP1 enhances HCV IRES activity by binding to the IRES near the Core start codon (Kim et al., 2004); in addition, its interaction with the $40 \mathrm{~S}$ ribosomal subunit facilitates $80 \mathrm{~S}$ complex formation (Park et al., 2011). NSAP1 has been suggested to play a role in HCV replication because knockdown of its expression reduces the replication of this virus (Liu et al., 2009). A common feature of these mentioned proteins above is the containing of multiple RNA recognition motifs (RRM); thus, it is of interest to analyze whether other proteins with RRMs are also involved in HCV replication.
RNA-binding proteins (RBPs), which bind to double or single-stranded RNA, play key roles in the post-transcriptional control of RNA. Previous reports have shown that RNA binding protein 24 (RBM24), which harbors a single RRM at its $\mathrm{N}$-terminus, is required for cardiovascular development and myogenesis because it regulates the stability and/or alternative splicing of the mRNAs of related genes (Jin et al., 2010; Poon et al., 2012; Xu et al., 2014; Yang et al., 2014). Gene array analysis has revealed the significant up-regulation of RBM24 during $\mathrm{HCV}$ infection. Considering its role in the post-transcriptional control of RNA, we analyzed the function of RBM24 in the HCV life cycle and found that it binds to both the 5'- and 3'-UTRs of HCV, inhibits HCV IRESmediated translation by interrupting $60 S$ ribosome recruitment and promotes $\mathrm{HCV}$ replication by linking the $\mathrm{HCV}$ 5'- and 3'-UTRs.

\section{RESULTS}

\section{RBM24 participates in HCV propagation}

Several host factors with RNA-binding domains have been previously reported to be involved in the control of $\mathrm{HCV}$ translation and/or replication. RBM24, which has been shown to be up-regulated by $\mathrm{HCV}$ infection by microarray analysis, was selected for further study. The up-regulation of RBM24 by HCV infection was first validated at the RNA and protein levels. As shown in Fig. 1A-D, the RBM24 mRNA level was significantly up-regulated in time- and viral dosedependent manners by J399EM and Jc1 infection, and its protein expression level was also increased by $\mathrm{HCV}$ infection (Fig. 1C).

The involvement of RBM24 in the HCV life cycle was then analyzed. Huh7.5.1 cells were transfected with siRNAs, including nonspecific siNC, siRBM24 targeting exon 2 of RBM24 and siHCV targeting the HCV IRES, and then were infected with Jc1. siHCV successfully restricted HCV replication, and it also inhibited the up-regulation of RBM24, further confirming that RBM24 expression was elevated by $\mathrm{HCV}$ infection (Fig. $1 \mathrm{E}$ and 1F). siRBM24 efficiently decreased the mRNA level of RBM24 (Fig. 1E) without significantly influencing cell viability. The silencing of RBM24 considerably reduced the HCV RNA level by approximately $70 \%$ at $24 \mathrm{hpi}$, and by $50 \%$ at $48 \mathrm{hpi}$ and $72 \mathrm{hpi}$, respectively, compared with that in siNC-transfected cells (Fig 1F). Consistently, the HCV NS3 protein expression level in siRBM24transfected cells was also significantly decreased (Fig. 1G). Virus propagation in siRBM24-transfected cells was impaired to a similar degree as the decrease in intracellular HCV RNA (Fig. 1H). As a result, the calculated assembly efficiency (the ratio of the number of supernatant HCV RNA copies to that of intracellular HCV RNA copies) and budding efficiency (the ratio of the HCV titer in the cell supernatant to that in cells) were similar in siRBM24- and siNC-transfected cells (Fig. $1 \mathrm{l}$ and $1 \mathrm{~J}$ ). These results indicate that the silencing of RBM24 expression reduced $\mathrm{HCV}$ replication and that this 

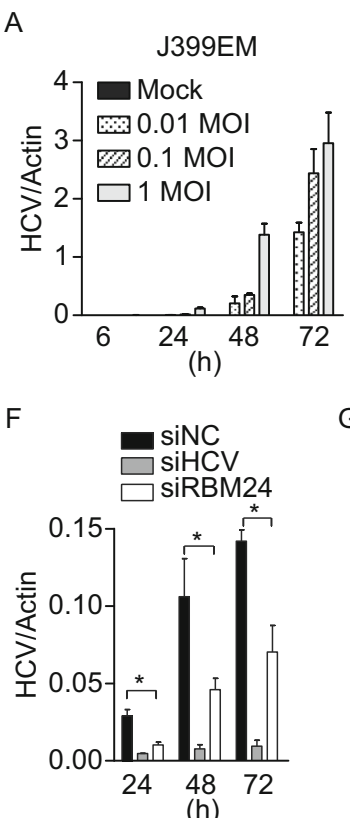
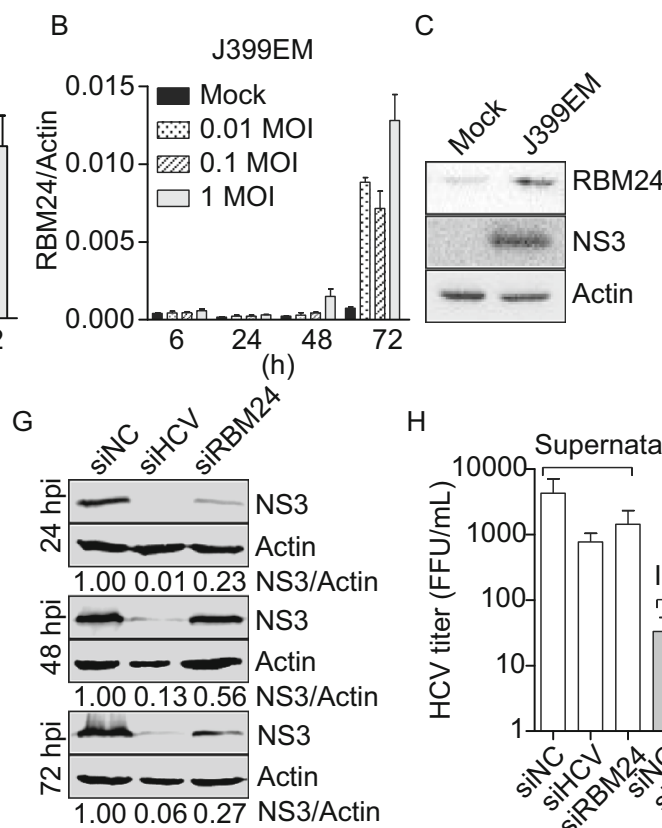

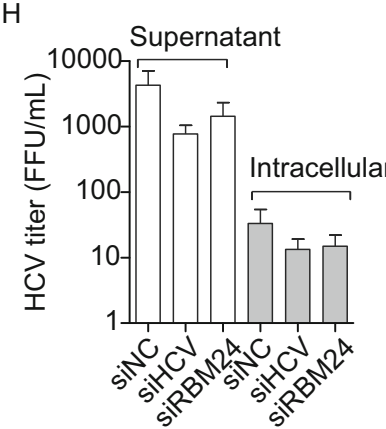

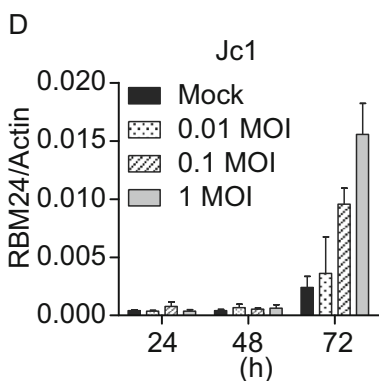

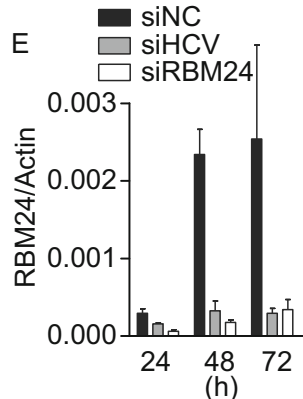

J

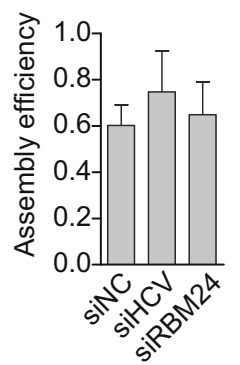

Figure 1. Participation of RBM24 in HCV life cycle. (A-C) Huh7.5.1 cells infected with J399EM of different MOls $(0,0.01,0.1$ and 1) were harvested at the indicated time points. (A and $B$ ) The intracellular HCV RNA levels $(A)$ and RBM24 mRNA levels (B) were quantified by qRT-PCR. The protein levels of HCV NS3 (0.1 MOI) and endogenous RBM24 were detected by WB at $72 \mathrm{hpi}(\mathrm{C})$. (D) The RBM24 mRNA levels in Jc1 infected Huh7.5.1 cells were quantified by qRT-PCR. (E-H) Huh7.5.1 cells were transfected with the indicated siRNAs and then infected with $\mathrm{Jc} 1$ at $1 \mathrm{MOI}$. The intracellular RBM24 mRNA (E) levels and HCV RNA (F) levels were quantified by qRT-PCR at the indicated time point. (G) The NS3 protein expression levels were detected by WB. $(H)$ The viral titers in supernatant and in cells at $72 \mathrm{hpi}$ were monitered. (I and J) The assembly efficiency (the ratio of the number of supernatant HCV RNA copies to that of intracellular HCV RNA copies) and budding efficiency (the ratio of the HCV titer in the cell supernatant to that in cells) were calculated.

reduction was not at the assembly or release step of the $\mathrm{HCV}$ life cycle.

\section{RBM24 participates in the translation and replication of HCV}

To determine the step of the HCV life cycle at which RBM24 is involved, the effect of RBM24 on viral entry, translation and subgenomic RNA replication was first studied using HCVpp, an HCV IRES reporter plasmid and a subgenomic replicon system. HCVpp entry efficiency, as indicated by the luciferase activity in HCVpp-transduced Huh7.5.1 cells, was not noticeably altered by RBM24 silencing or overexpression (Fig. 2A), suggesting the lack of influence of RBM24 on HCV entry. pHCV-IRES, a bicistronic reporter plasmid that expresses renilla luciferase in a $5^{\prime}$ cap-dependent manner in addition to firefly luciferase directed by HCV IRES, was used to determine the effect of RBM24 on HCV translation in the context of RBM24 knockdown or overexpression. Though RBM24 silencing didn't influence the IRES mediated translation (Fig. 2B, left), a dose-dependent inhibition of $\mathrm{HCV}$ IRES-dependent translation compared with the cap-dependent translation by RBM24 overexpression was observed
(Fig. 2B, right). The inhibition of HCV IRES-dependent translation by RBM24 was further validated by cell-free translation assay with a monocistronic construct composed of HCV IRES and the firefly luciferase coding sequence. In this system, the presence of rhRBM24 protein significantly reduced HCV IRES-mediated translation in a dose dependent manner (Fig. 2C). Thus, RBM24 showed an inhibitory effect on HCV IRES-dependent translation in both the bicistronic and monocistronic constructs. Furthermore, the replication-defective SGR-Luc-JFH1-GND construct with an inactivation mutation (GDD-to-GND) in the active site of NS5B was used to analyze the influence of RBM24 on HCV IRES activity. Huh7.5.1 cells were transfected with pcDNA3.1 or pRBM24 first, and then electroporated with the in vitro transcribed RNA (SGR-Luc-JFH1-GND). The intracellular HCV RNA were monitored by realtime RT-PCR immediately after the electroporation and served as input RNA. When normalized by the abundance of input RNA, the luciferase activity at $4 \mathrm{~h}$ post electroporation was decreased by RBM24 overexpression, suggesting that RBM24 inhibit the translation efficiency of HCV (Fig. 2D). Taken together, these results indicate that RBM24 is not involved in $\mathrm{HCV}$ entry but that it has an inhibitory effect on HCV IRES activity. 


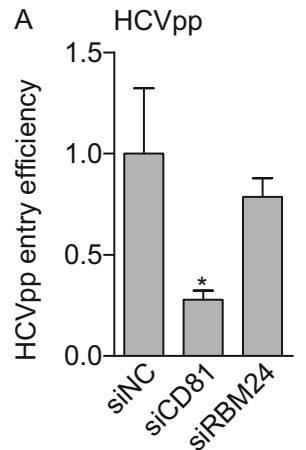

C

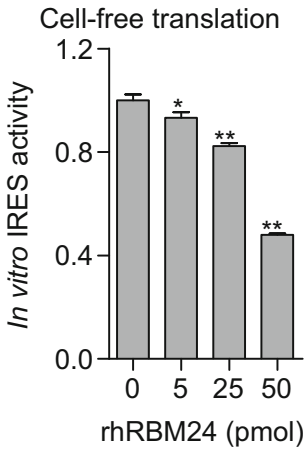

$\mathrm{F}$

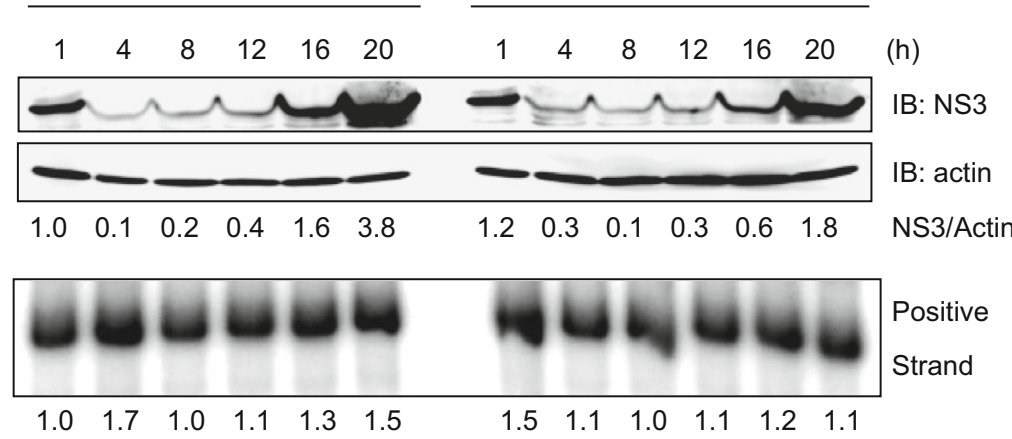

B

pHCV-IRES
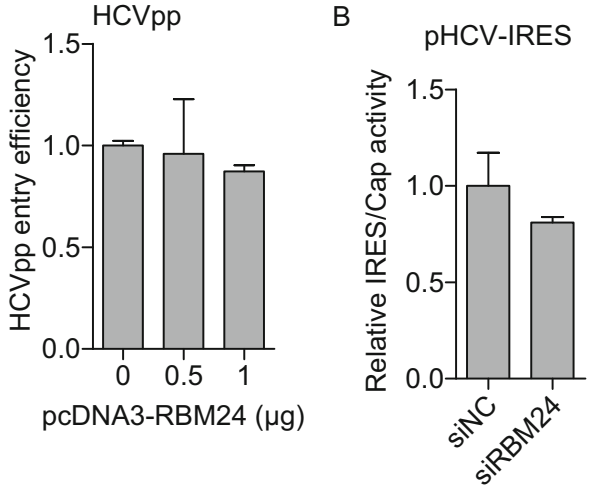

E

$>$ SGR-LuC-JFH1-GND

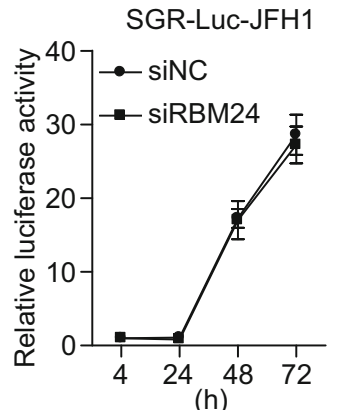

(h)

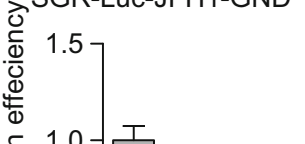

它

siRBM24
pHCV-IRES

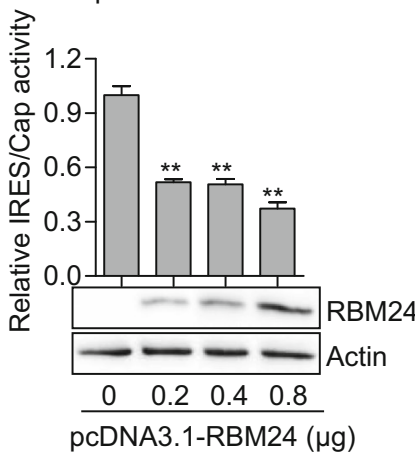

SGR-Luc-JFH1

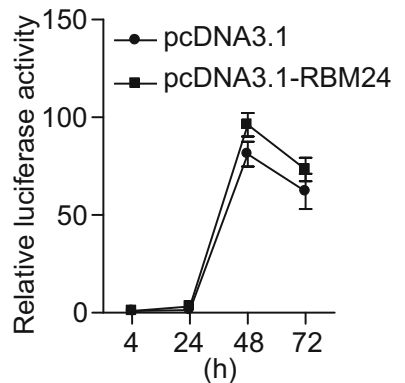

G

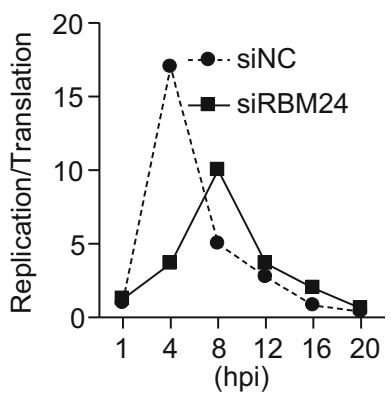

Figure 2. The involvement of RBM24 in HCV translation and replication. (A) Huh7.5.1 cells were transfected with the indicated siRNAs or RBM24 expression plasmids and transduced with HCVpp. Cell lysates were collected at $48 \mathrm{~h}$ post-transduction, and luciferase activity was measured. (B) Huh7.5.1 cells were transfected with indicated siRNAs or RBM24 expression plasmids together with pHCV-IRES. Cell lysates were collected at $24 \mathrm{~h}$ post-transfection, and luciferase assay was performed. HCV IRES-dependent translation relative to cap-dependent translation was calculated and normalized. (C) The RNA fragment containing HCV IRES and the firefly luciferase coding sequence was incubated with either rhRBM24 or BSA in RRL at $30^{\circ} \mathrm{C}$ for 15 min. Luciferase activity was determined with Steady-Glo®. (D) Huh7.5.1 cells were transfected with pcDNA3.1 or pcDNA3.1-RBM24, and then electroporated with the replication deficiency subgenomic RNA, SGR-Luc-JFH1-GND. Luciferase assay was performed at the indicated time points post-electroporation. (E) Huh7.5.1 cells were transfected with siNC or siRBM24, or a control vector or pcDNA3.1-RBM24 plasmid, and then electroporated with HCV subgenomic RNA, SGR-Luc-JFH1. The replication of HCV RNA was monitored by assessing luciferase expression by luciferase assay at the indicated time points post-electroporation. (F) Huh7.5.1 cells transfected with siNC or siRBM24 were infected with $\mathrm{Jc} 1$ at an $\mathrm{MOI}$ of 5 . The infection was synchronized by incubation at $4^{\circ} \mathrm{C}$ for $1 \mathrm{~h}$ to allow attachment and at $37^{\circ} \mathrm{C}$ for $1 \mathrm{~h}$ to allow virus entry. Total RNA and protein were extracted at the indicated time points post-infection, and the HCV NS3 expression and HCV RNA levels were monitored by Western blotting and RPA, respectively. The NS3 protein level normalized against beta-actin and the HCV RNA level were analyzed by densitometry and are presented as numbers below the figure. (G) The ratio of replication (HCV RNA) to translation (NS3 protein) efficiency was calculated. 
Surprisingly, no significant difference in the replication of SGR-Luc-JFH1 was observed between vector- and RBM24transfected Huh7.5.1 cells or between siNC- and siRBM24transfected Huh7.5.1 cells (Fig. 2E). Further considering the fact that HCV propagation was reduced in siRBM24-transfected cells (Fig. 1), the inhibition of HCV IRES activity by RBM24 implies that RBM24 is probably required for replication of genomic RNA. Then the profiles of HCV replication and translation were analyzed within $24 \mathrm{hpi}$ in RBM24 knockdown cells. For this purpose, Huh7.5.1 cells transfected with siNC or siRBM24 were infected synchronizationally with $\mathrm{Jc} 1$ at an $\mathrm{MOI}$ of 5 by sequentially incubation at $4^{\circ} \mathrm{C}$ for $1 \mathrm{~h}$, washing with PBS and incubation at $37^{\circ} \mathrm{C}$ for $1 \mathrm{~h}$. HCV NS3 expression and RNA levels were monitored by Western blotting and RPA, respectively, at the indicated time points. In siNC-transfected cells, the NS3 protein expression was detectable at $1 \mathrm{hpi}$, decreased at $4 \mathrm{hpi}$, and then gradually increased, and a sharp increase in the NS3 protein level was observed at $16 \mathrm{hpi}$ and $20 \mathrm{hpi}$, while the HCV RNA level exhibited an increase at $4 \mathrm{hpi}$, decrease at $8 \mathrm{hpi}$ and then a gradual increase (Fig. $2 \mathrm{~F}$ ). The ratio of replication to translation efficiency peaked at $4 \mathrm{hpi}$ in siNC-transfected cells (Fig. 2G), suggesting that the first round of translation of the released HCV RNA occurred within $1 \mathrm{hpi}$ and that the switch from translation to replication probably took place before $4 \mathrm{hpi}$. The protein and RNA profiles of $\mathrm{HCV}$ were markedly different in siRBM24-transfected cells. First, NS3 protein expression was relatively higher at $1 \mathrm{hpi}$ and $4 \mathrm{hpi}$ in siRBM24-transfected cells compared with that in siNC transfected cells, and its expression was the lowest at $8 \mathrm{hpi}$; however, its expression was significantly lower at $20 \mathrm{hpi}$ in siRBM24-transfected cells because a sharp increase in NS3 only occurred at $20 \mathrm{hpi}$. Second, no significant increase in the HCV RNA level was observed at $4 \mathrm{hpi}$ in siRBM24transfected cells. Third, the peak in the replication to translation ratio was reduced and delayed to $8 \mathrm{hpi}$. These results suggested that the silencing of RBM24 stimulated the initial translation of HCV proteins but inhibited and delayed replication of HCV genome.

\section{RBM24 interacts with HCV RNA}

To determine the manner by which RBM24 is involved in $\mathrm{HCV}$ translation and replication, the interaction of RBM24 with HCV RNA was first examined. RIP was performed using a lysate of Jc1-infected Huh7.5.1 cells in which Flag-RBM24 was over-expressed. The precipitant was analyzed by qRTPCR or RPA. As shown in Fig. $3 A$ and $3 B$, a significant amount of HCV RNA was co-immunoprecipitated with FlagRBM24 by a Flag tag antibody compared with IgG control, suggesting the association of RBM24 with HCV genomic RNA in HCVcc-infected cells. Further, RBM24 co-localized with HCV double strand RNA (dsRNA) in cytoplasm in Jc1 infected Huh7.5.1 cells (Fig. 3C) as shown by immunofluorescence detection, supporting the association of RBM24 with HCV RNA.
Non-specific CLIP was then performed to identify the RBM24 binding sequences in HCV RNA. Various HCV RNA fragments labeled with ${ }^{32} \mathrm{P}$ were subjected to CLIP together with the Flag-RBM24 containing cell lysate. Fragments of the HCV 5'-UTR (J1-360) and 3'-UTR (J9440-9678), but not of the regions containing Core (J336-553, J530-897, and J878-1484) or the NS5B coding region elements (J91169463), were strongly crosslinked to Flag-RBM24 (Fig. 3D). In further CLIP analysis, the $5^{\prime}$-UTR region was divided into 2 fragments, J1-149 (SL I-SL II) and J127-360 (SL III-SL IV), according to the secondary structure, and the $3^{\prime}-\mathrm{UTR}$ region was divided into J9440-9578 (VSL2-polyU tract) and J95789678 (3'-X region). The results shown in Fig. 3E indicate that nt 1-149, nt 127-360 and nt 9440-9578 in the HCV RNA $5^{\prime}$-UTR and $3^{\prime}$-UTR regions interacted with Flag-RBM24. Neither deletion of nt 5-19 corresponding to SLI (J1-360 $\Delta \mathrm{I})$, nt 43-119 corresponding to SLII (J1-360 $\mathrm{II})$ nor nt 65-100 corresponding to the upper part of SLII (J1-360 $\Delta \mathrm{llb})$ could abolish the crosslinking of the HCV 5'-UTR to Flag-RBM24 (Fig. 3F).

The interactions of RBM24 with the HCV 5'-UTR and 3'UTRs were further validated by biotin pull-down assay. Different fragments of the $5^{\prime}$-UTR and $3^{\prime}$-UTRs were labelled with biotin and incubated with a lysate of 293T cell overexpressing RBM24. Biotinylated RNA and bound proteins were then isolated on streptavidin agarose and analyzed by Western blotting with an RBM24 antibody. Consistent with the results of CLIP assay, the fragments J1-360, J1-149, J9440-9678 and J9440-9578 efficiently pulled down the RBM24 protein (Fig. 3G). Interestingly, RBM24 was also coprecipitated with the $3^{\prime}-X$ fragment, which did not crosslink to Flag-RBM24 as shown by CLIP assay (Fig. 3F). Taken together, these results demonstrated that RBM24 interacted with the HCV 5'-UTR and 3'-UTR (nt 9440-9578).

\section{RBM24 blocks 80 S ribosome assembly on HCV IRES}

HCV IRES-mediated translation is initiated by $80 \mathrm{~S}$ ribosomes, which are sequentially formed by 405 subunit binding, elF3 and ternary complex binding, GTP hydrolysis, elF release, and 60S subunit binding (Lukavsky, 2009). To elucidate the mechanism underlying the inhibition of HCV IRES activity by RBM24, ribosome assembly was examined in a rabbit reticulocyte lysate (RRL) system. Biotin-labelled HCV IRES (J1-360) RNA together with rhRBM24 protein or BSA control were incubated with $\mathrm{RRL}$, and the resulting ribosomal complexes were separated by sucrose density gradient ultracentrifugation and analyzed by dot blot. Consistent with previous reports, 805 ribosome formation was observed after 15 min of incubation in the BSA control group, whereas in the presence of recombinant RBM24, the 80 S peak was significantly lower, and most of the RNA was retained in the 40/48S peaks (Fig. 4). Thus, the inhibitory effect of RBM24 on HCV IRES activity was due to the inhibition of $80 S$ ribosome assembly occurring at the step after $40 \mathrm{~S}$ ribosome binding. 
A

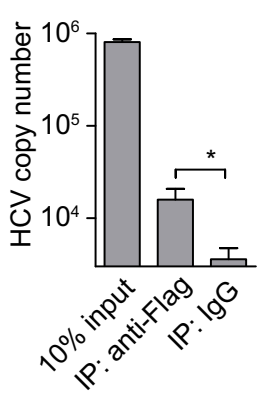

B

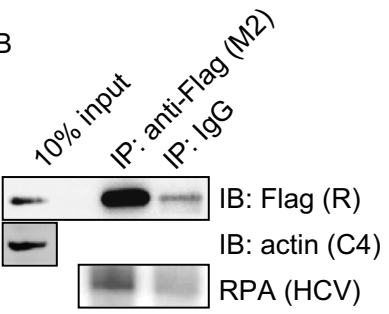

C
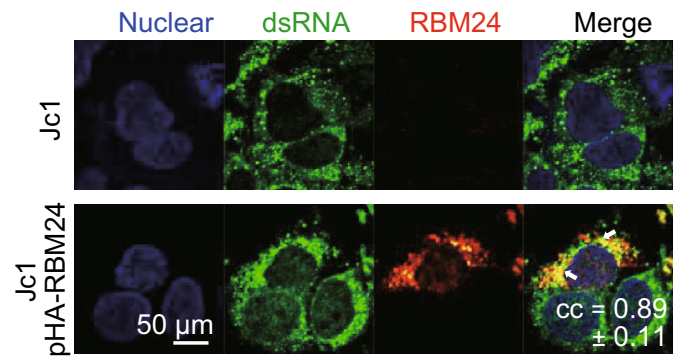

D
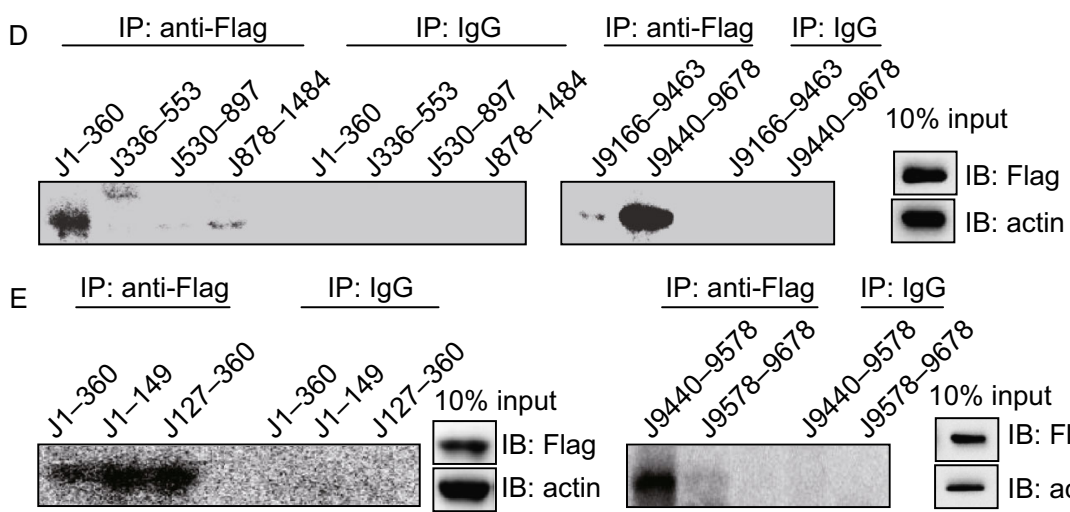

F
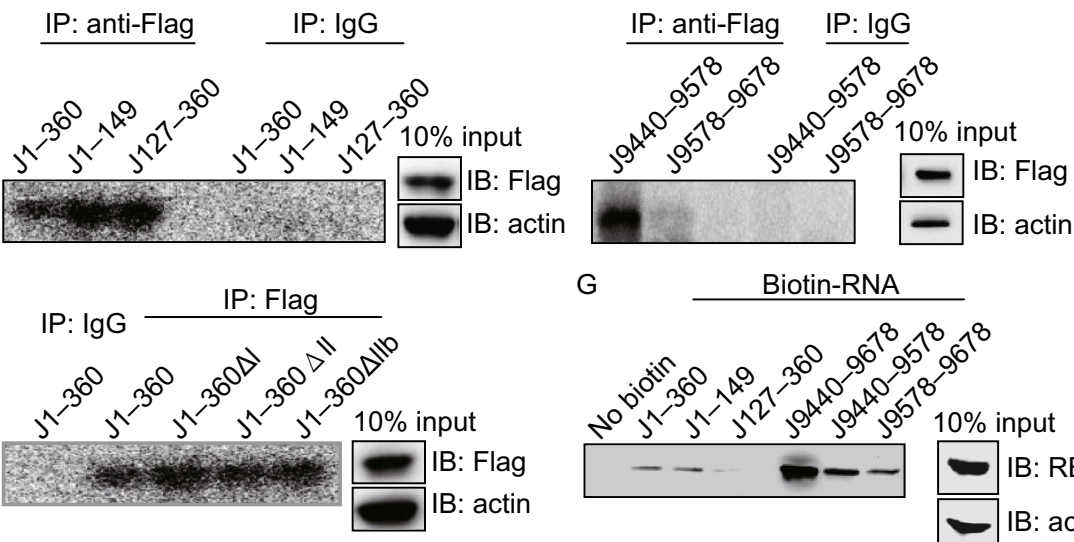

G

Biotin-RNA

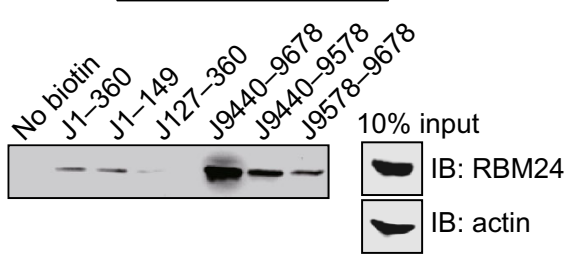

Figure 3. The interaction between RBM24 and HCV RNA sequences. (A and B) Huh7.5.1 cells were transfected with pFlagRBM24 and infected with $\mathrm{Jc} 1$ at an $\mathrm{MOI}$ of 0.1 . The cells were harvested at $72 \mathrm{hpi}$ as described in experimental procedures and immunoprecipitated with either an anti-Flag mouse monoclonal antibody (Flag) or a nonspecific mouse control antibody (lgG). Precipitated HCV RNA was detected by qRT-PCR (A) or RPA (B), and the precipitated NS3, RBM24 and actin were detected by Western blot (B). (C) Huh7.5.1 cells were transfected with vectore or pHA-RBM24 and then infected with Jc1 at an MOI of 1. The localization of double strand RNA and RBM24 protein were detected by immunofluorescence using the J2 antibody and HA antibody respectively. The nuclei were stained with Hoechst 33258. (D-F) A lysate of 293T cells transfected with pFlag-RBM24 was crosslinked with the indicated ${ }^{32} \mathrm{P}$-labeled HCV fragments. The crosslinked nucleotides-proteins were immunoprecipitated with either an anti-Flag mouse monoclonal antibody (Flag) or a nonspecific mouse control antibody (lgG) and detected by autoradiography. The input proteins were detected by Western blot. (G) A lysate of 293T cells transfected with pcDNA3.1-RBM24 was incubated with the indicated biotin-labeled HCV fragments and affinity-precipitated with streptavidin beads. RBM24 protein was detected by Western blot. 


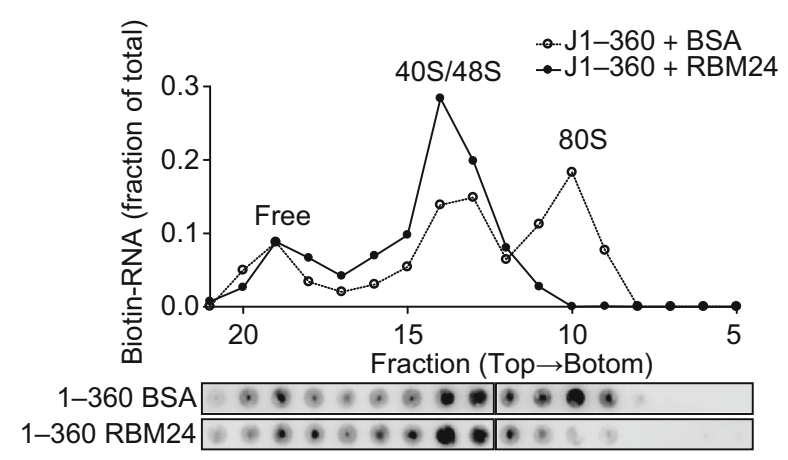

Figure 4. RBM24 blocks 80 S ribosome assembly on HCV IRES. Biotin-labeled JFH1 nt 1-360 together with rhRBM24 or $\mathrm{BSA}$ were incubated in $\mathrm{RRL}$ at $30^{\circ} \mathrm{C}$ for $15 \mathrm{~min}$. The ribosome complexes were separated by sucrose gradient ultracentrifugation. The distribution of biotin-RNA was detected by dot-blot assay with streptavidin-HRP and analyzed by densitometry (fractions 5-21 were shown).

\section{RBM24 affects the interaction of Core protein with HCV IRES}

Viral and host factors interact and work together to control $\mathrm{HCV}$ replication. Moreover, the HCV structural protein Core and non-structural protein NS3 have been reported to bind to the HCV IRES as RBM24. Thus we next analyzed the interplay between RBM24, HCV proteins and the HCV IRES. Interestingly, RBM24 interacted with the HCV Core and NS3 proteins but not the NS5A or NS5B proteins, as shown by co-immunoprecipitation assay (Fig. 5A and 5B). Consistently, immunofluorescence results showed that RBM24 was partially co-localized with HCV Core and NS3 protein, while no obvious colocalization of RBM24 with NS5A was found in Huh7.5.1 cells (Fig. 5C). Both the Core and NS3 proteins have been proven to be trans-modulating factors in HCV replication (Shimoike et al., 1999; Ray and Das, 2011). Thus we then analyzed whether RBM24 influences the interactions of the HCV Core and NS3 proteins with the HCV IRES. To this end, we performed biotin pull-down assay with a biotinylated HCV 5'-UTR (J1-360) and a cell lysate containing Core or NS3 in the presence or absence of RBM24. As shown in Fig. 5D, the co-expression of RBM24 with the Core and NS3 proteins did not influence their expression. However, the amount of HA-Core precipitated with the HCV $5^{\prime}$-UTR was significantly increased by the overexpression of RBM24, while the amount of HA-NS3 coprecipitated with the HCV 5'-UTR was not affected. In addition, the silencing of RBM24 expression in Huh7.5.1 cells significantly decreased the amount of HA-Core and HA-NS3 coprecipitated with the HCV 5'-UTR (Fig. 5E). The effect of Core on HCV IRES activity was detected in the background of siRBM24 transfection. Results showed that the knockdown of RBM24 expression slightly reduced the inhibitory effect of Core on IRES activity (Fig. 5F). These results suggested that RBM24 regulates the interaction between the Core and the HCV 5'UTR.

RBM24 enhances the interaction between the HCV $5^{\prime}$ and $3^{\prime}$-UTRs

In addition to the $5^{\prime}$-UTR, RBM24 can bind to the $3^{\prime}$-UTR of HCV RNA (Fig. 3). The long-range RNA-RNA interaction of the $5^{\prime}$ - and $3^{\prime}$-UTRs which is mediated by direct interaction of the $5^{\prime}$ - and $3^{\prime}$-UTRs or by trans factors, is thought to play a role in viral translation modulation and in the switch from protein synthesis to RNA replication. Thus it is possible that RBM24 participates in translation and replication by enhancing the interaction of the HCV $5^{\prime}$-UTR and $3^{\prime}$-UTRs. To test this hypothesis, this interaction was assessed by streptavidin pull-down assay. Streptavidin beads were coated with a biotinylated HCV 5'-UTR and then incubated with a ${ }^{32} \mathrm{P}$-labeled $3^{\prime}-\mathrm{UTR}$ in the presence or absence of recombinant RBM24. The amount of $3^{\prime}-U T R$ RNA that interacted with the coated beads was analyzed by ureaPAGE. The results showed that the interactions of J1-360 and J1-149 with J9440-9678 were significantly enhanced by rhRBM24 compared with the unrelated protein BSA (Fig. 6A). Competition experiments revealed that the interaction between biotin-J1-149 and ${ }^{32}$ P-J9440-9678 enhanced by RBM24 could be out-competed by increasing the amount of cold J1-149 or J9440-9678 but not that of unrelated RNA (Fig. 6B), indicating the specificities of the interactions between RBM24 and these HCV RNA fragments.

RBM24 only has one RRM domain, and the manner by which it interacts with both the 5'- and $3^{\prime}$-UTRs and enhances their interaction is unknown. RBM24 has an alanine-rich domain containing 2 uninterrupted polyalanine stretches at the C-terminus which is thought to mediate oligomerization and self-aggregation (Measey et al., 2009). Indeed, Flagand HA-RBM24 co-immunoprecipitated when they were coexpressed in 293T cells (Fig. 6C), suggesting a potential selfinteraction of RBM24. Hence, RBM24 is a trans-acting factor that enhances the interaction between the 5'-UTR and $3^{\prime}$ UTRs of the HCV genome; therefore it may participate in the control of HCV replication.

\section{DISCUSSION}

After being released into the cytoplasm, the genomic RNA of $\mathrm{HCV}$ is first used as template for protein synthesis. Once viral proteins are synthesized, the viral RNA is replicated, beginning with negative-strand RNA synthesis using the genomic RNA as a template. The fine-tuned regulation of the switch from translation to replication has still not been fully elucidated. In this study, we identified RBM24 as a host factor involved in both translation and RNA replication in $\mathrm{HCV}$ life cycle. First, RBM24 inhibits the HCV IRES activity by binding to the $5^{\prime}$-UTRs of HCV RNA and impairing $80 S$ 


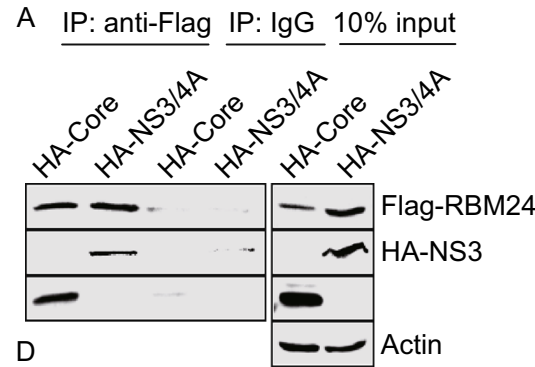

B

Streptavidin pulldown

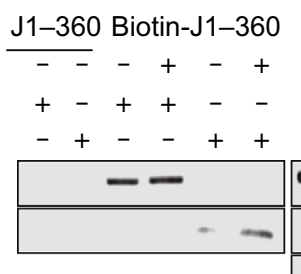

E

Streptavidin pulldown

J1-360 Biotin-J1-360 10\% input

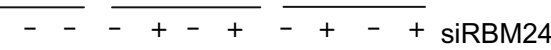

$+-++--++-\quad$ pHA-NS3/4A

-+-+++-++ pHA-Core

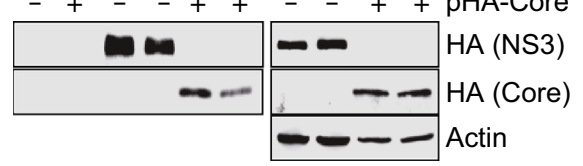

$\underline{\text { IP: anti-Flag IP: IgG } 10 \% \text { input }}$

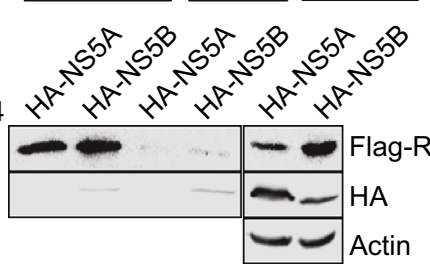

C

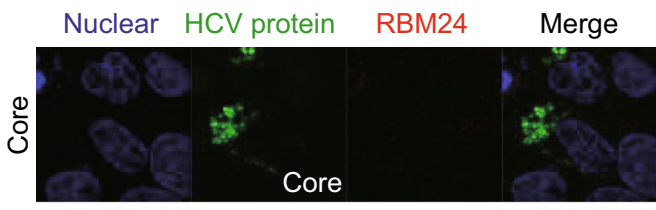

¿ั
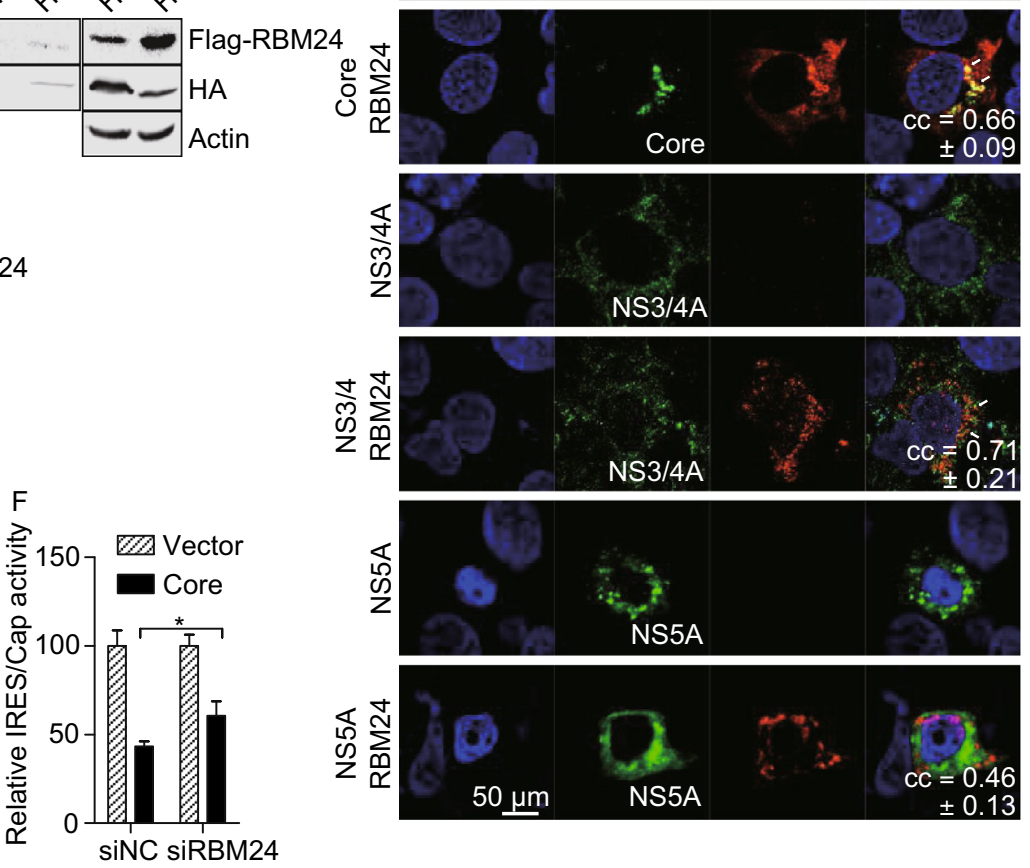
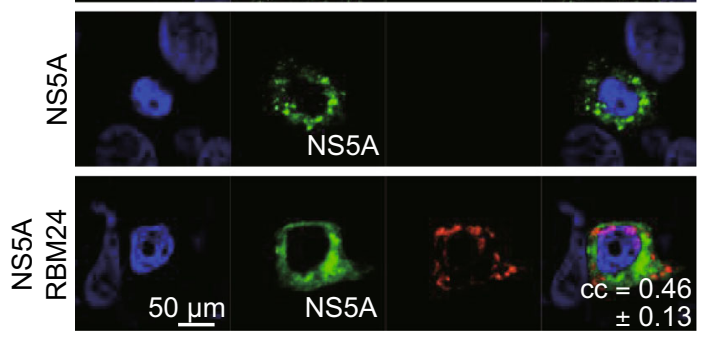

Figure 5. The interactions between RBM24 and HCV proteins. (A) 293T cells were transfected with Flag-RBM24 together with HA-Core or HA-NS3/4A. Cell lysates were immunoprecipitated with either an anti-HA mouse monoclonal antibody (HA) or a nonspecific mouse control antibody $(\mathrm{IgG})$ in the presence of RNase A. Immunoprecipitated proteins were detected with an anti-HA rabbit monoclonal antibody (HA) or an anti-DYKDDDDK rabbit polyclonal antibody (Flag) correspondingly. (B) Co-IP was performed with the lysate of 293T cells transfected with pFlag-RBM24 and pHA-NS5A, or with pFlag-RBM24 and pHA-NS5B. (C) Huh7.5.1 cells were transfected with HCV protein (Core, NS3/4A or NS5A) expression plasmids together with pHA-RBM24. The localization of Core, NS3/4A, NS5A and RBM24 was detected by immunostaining with HA and Flag antibodies. The nuclei were stained with Hoechst 33258. (D) 293T cells were co-transfected with pcDNA3.1-RBM24 with either pHA-Core or pHA-NS3/4A. The cell lysates were incubated with the indicated biotin-labeled HCV fragments and affinity-precipitated with streptavidin beads. Precipitated proteins were detected by Western blot with the corresponding antibodies. (E) Huh7.5.1 cells were transfected with siRBM24 as described in experimental procedures and then transfected with either pHA-Core or pHA-NS3/4A. Cell lysates were incubated with the indicated biotin-labeled HCV fragments and affinity precipitated with streptavidin beads. Precipitated proteins were detected by WB with the corresponding antibodies. (F) Huh7.5.1 cells were transfected with indicated siRNAs first then transfected with pHCV-IRES and pHACore. Luciferase assay was performed $24 \mathrm{~h}$ later.

ribosome assembly on the HCV IRES. RBM24 also enhances the interaction of Core and 5'-UTRs of HCV RNA, which suppress the expression of HCV. Furthermore, RBM24 enhances the interaction between the HCV $5^{\prime}$ - and $3^{\prime}$-UTR that is required for efficient RNA replication and therefore may function at the switch from translation to replication.

$\mathrm{HCV}$ protein translation is mediated by the highly conserved IRES structure and $80 \mathrm{~S}$ ribosome assembly on the IRES is a process including multiple steps that are mediated by specific IRES structural domains. The SLII domain is of great interest because it is indispensable for the conformational change of the 40 S subunit induced by IRES binding (Spahn et al., 2001; Filbin and Kieft, 2011; Boehringer et al.,
2005). Interaction of the SLII domain with ribosomal protein 5 (RPS5) is required for $80 \mathrm{~S}$ ribosome assembly (Bhat et al., 2015), and has been reported to promote elF2-GDP release. Further, deletion of this domain blocks $80 \mathrm{~S}$ assembly after $48 \mathrm{~S}$ complex formation (Locker et al., 2007). RBM24 blocks the formation of the $80 \mathrm{~S}$ ribosome complex after $40 / 48 \mathrm{~S}$ complex formation, similar to what occurs following SLII domain deletion. It is likely that the binding of RBM24 to the $5^{\prime}$-UTR does not influence the interaction of the IRES with $40 \mathrm{~S}$ ribosome but it does interfere with the $80 \mathrm{~S}$ ribosome assembly.

Besides affecting the 80S ribosome assembly, RBM24 may influence HCV IRES activity through interaction with 


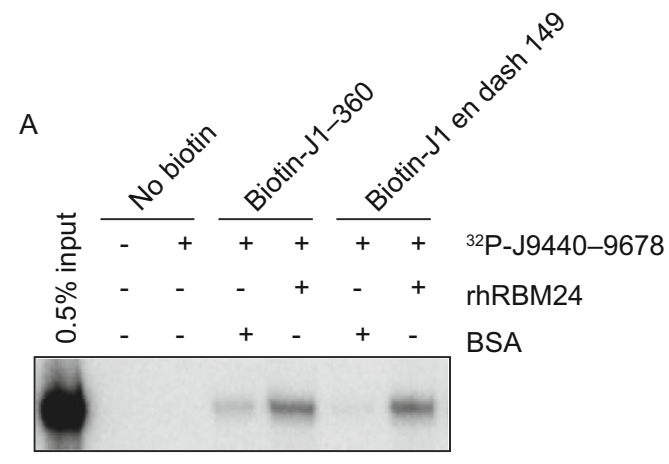

C

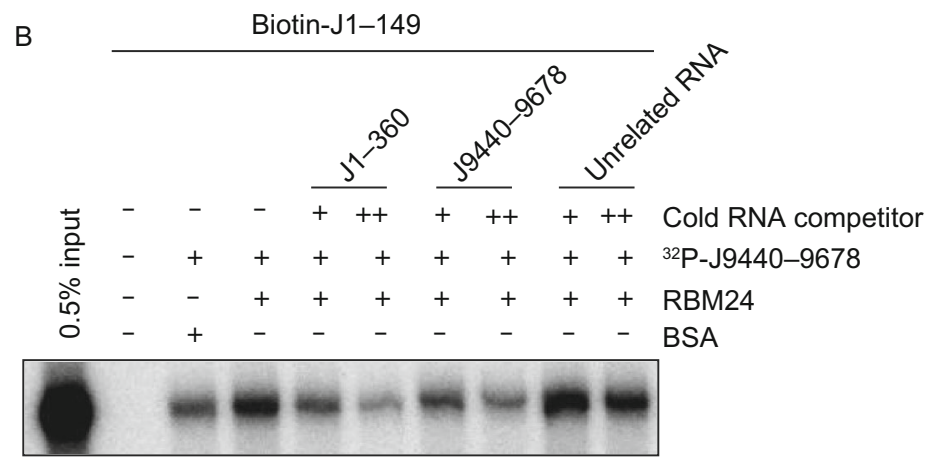

Figure 6. RBM24 enhances the interaction between the HCV 5'- and $3^{\prime}$-UTRs. (A) Interaction between the 5'-UTR (J1-360 or J1149) and 3'-UTR (J9440-9678) was analyzed in the presence or absence of rhRBM24, as described in the experimental procedures. Precipitated RNAs were analyzed on a $6 \%$ urea-PAGE gel and by autoradiography. (B) The effects of cold RNA competitors (J1-360 and J9440-9678) on the interaction between HCV J1-149 and J 9440-9678 were analyzed. (C) The 293T cells were co-transfected with pFlag-RBM24 and pHA-RBM24. Cell lysates were immunoprecipitated with either an anti-Flag mouse monoclonal antibody (Flag), an anti-HA mouse monoclonal antibody (HA) or a nonspecific mouse control antibody (IgG). Precipitated proteins were detected with an anti-HA rabbit monoclonal antibody (HA) or an anti-DYKDDDDK rabbit polyclonal antibody (Flag) correspondingly.

HCV proteins. HCV Core not only functions as a structural nucleocapsid protein but also inhibits the expression of HCV (Shimoike et al., 1999; Shimoike et al., 2006; Tanaka et al., 2000). Here we found that RBM24 interacts with both 5 '-UTR of HCV RNA and Core protein, and enhances the interaction of Core and 5'-UTR of HCV, which is thought to be a mechanism of translation inhibition (Shimoike et al., 1999). It has been reported that HCV NS3 binds to the SLIV and hinders the interaction of La protein with HCV IRES, resulting in inhibition of HCV-IRES activity (Ray and Das, 2011). Although we found that RBM24 interacted with NS3 protein, its presence did not influence the interaction of NS3 and the 5'-UTR. Thus, RBM24 may also suppress the expression of $\mathrm{HCV}$ through its interaction with Core but not NS3 protein.

Long-range RNA-RNA interactions of HCV RNA either mediated directly or by protein-RNA interactions are required for efficient replication and play a crucial role in switching among different steps of the HCV life cycle, such as the translation-replication and replication-assembly switches (Shetty et al., 2013). RBM24 binds to both the 5'-UTR and 3'UTRs of HCV, and although it contains only one RNAbinding domain, it has the ability to form dimers or oligomers. As a result, it could act as a protein bridge to facilitate long- range RNA interactions between the $5^{\prime}$ - and $3^{\prime}$-UTRs of HCV genome. Knockdown of the endogenous expression of RBM24 in Huh7.5.1 cells enhances and prolongs translation and delays the translation-replication switch during the early events after virus entry (Fig. $2 F$ and $2 G$ ); thus RBM24 is thought to inhibit translation and promote replication and to play a role in this switch. As mentioned above, the translation and replication of $\mathrm{HCV}$ are regulated in complex manners by multiple factors, including cis- and trans-factors, the most studied of which is La protein. According to previous reports, multi-round translation of HCV RNA is enhanced by La protein (Kumar et al., 2013) as the HCV RNA genome is released into the cytoplasm. When the viral protein accumulates to a threshold in the presence of NS3 protein, Lamediated enhancement of translation is inhibited, and La protein promotes the replication of HCV RNA by facilitating interaction of the 5'- and 3'-UTRs (Ray and Das, 2011). Furthermore, RNA-binding proteins have been demonstrated to be interacted with each other, for example, La protein and PCBP2 form an oligomer, and PCBP2 and polypyrimidine tract binding protein (PTB) interact with $\mathrm{La}$ protein (Fontanes et al., 2009). Very recently, another RNA binding protein, HuR was shown to interact with $3^{\prime}$-UTR of 
HCV genome, compete with PTB but facilitate La binding to the 3'-UTR (Shwetha et al., 2015). In contrast with La protein, RBM24 is thought to inhibit translation but to facilitate the HCV $5^{\prime}$ - and $3^{\prime}$-UTR interaction required for multi-round replication. The fact RBM24 silencing only reduced HCV replication in HCVcc system but not in subgenomic replicon cells implied that the modulation of $\mathrm{HCV}$ replication by RBM24 requires HCV structure proteins especially the Core protein. It will be interesting to reveal whether RBM24 interacts with La protein as well as other trans-acting factors, in addition to how RBM24 and these proteins function together during the replication-translation switch.

Although the expression of RBM24 has been shown to be relatively low in the liver in previous reports (Miyamoto et al., 2009), its mRNA level in HCV infected Huh7.5.1 cells could rise to a high level in this study compared with the copy number of the house keeping gene actin. Meanwhile, we observed high signal intensity in the liver with inflammation by immunohistochemistry (data not shown). Thus, the upregulation of RBM24 by HCV could be a consequent of $\mathrm{HCV}$ induced inflammatory response and the balance of $\mathrm{HCV}$ translation and replication controlled by RBM24 might be involved in the establishment or maintenance of viral persistence, which is a major characteristic of HCV infection.

Previous reports have shown that RBM24 regulates the stability and/or alternative splicing of the mRNAs of different genes. However, overexpression of RBM24 did not affect the stability of HCV RNA (data not shown). Thus, RBM24 regulate the viral protein expression in a novel way. The binding of RBM24 to RNA could be either sequence-dependent or structure-dependent, and it could interact with different RNAs and possibly be involved in the replication of other viruses, as have been reported for the binding of PTB and La protein to the RNAs of encephalomyocarditis virus (EMCV), Japanese encephalitis virus (JEV) and HBV (Vashist et al., 2011; Vashist et al., 2009; Heise et al., 1999; Horke et al., 2002; Kim and Jeong, 2006; Kaminski and Jackson, 1998; Zang et al., 2001). Indeed, our results demonstrate the involvement of RBM24 in the regulation of VSV and HBV replication (data not shown). Thus, it could be a common regulator for virus replication.

In summary, we identified RBM24 as a host factor involved in both translation and RNA replication in HCV life cycle. RBM24 binds to both the $5^{\prime}$ - and 3 '-UTRs of HCV RNA, impairing $80 \mathrm{~S}$ ribosome assembly on the HCV IRES and enhancing the interaction between the HCV 5'- and 3'UTR that is required for efficient RNA replication and therefore may function at the switch from translation to replication.

\section{MATERIALS AND METHODS}

Cell culture

Huh7.5.1 cells (kindly provided by Prof. Frank Chisari) and 293T cells were cultured in Dulbecco's modified Eagle medium (DMEM) with $2 \mathrm{mmol} / \mathrm{L}$ of glutamine (Gibco®, 12100-046),10\% fetal bovine serum (FBS) (Gibco $\AA$, 10099-141) and $100 \mathrm{U} / \mathrm{mL}$ of penicillinstreptomycin (Gibco®, $15140-122$ ) at $37^{\circ} \mathrm{C}$ in a $5 \% \quad \mathrm{CO}_{2}$ atmosphere.

\section{Virus production and titration}

The chimeric construct, Jc1 (kindly provided by Prof. T. Pietschmann and Prof. R. Bartenschlager), was linearized, in vitro-transcribed and electroporated into Huh7.5.1 cells as previously described ( $\mathrm{Pi}$ etschmann et al., 2006). The virus in the supernatant was concentrated and purified by PEG 8,000 and ultracentrifugation sequentially, and then titered by immunofluorescence staining with NS3 antibody 8 G-2 (Abcam®, ab65407) (Jones et al., 2011). The J399EM virus which is derived from the JFH-1 virus (kindly provided by Takaji Wakita) by inserting EGFP into the NS5A, was prepared as previously described (Zhu et al., 2014). The HCV pseudoparticle (HCVpp) was generated by transfection of 293T cells with pNL4.3. lucR-E- and pcDNA3.1-E1E2 (a gift from Jin Zhong) plasmids (Zhu et al., 2014).

To measure the intracellular virus titers, cells were washed and collected in $200 \mu \mathrm{L}$ PBS and lysed by 3 rounds of freezing and thawing. Jc1 virus was titrated by immunostaining with the NS3 antibody as described by Jones et al. (2011). Briefly, Huh7.5.1 cells were seeded in 8-well chamber slides and infected with 10-foldserially diluted virus. The infectious medium was removed and replaced with fresh medium $4 \mathrm{~h}$ after infection. $72 \mathrm{~h}$ post infection, cells were fixed and stained with anti-NS3 antibody. Viral titers were expressed as the number of focus-forming unit (FFU) per $\mathrm{mL}$. J399EM was titrated by endpoint dilution assay using EGFP as indicator (Zhu et al., 2014).

\section{Plasmid construction}

The HCV protein expression plasmids pXJ40-HA-Core, pXJ40-HANS3/4A, pXJ40-HA-NS5A and pXJ40-HA-NS5B have been described previously (Guo et al., 2014). The ORF of human RBM24 transcript 001 (ENST00000379052) was amplified using cDNA from HeLa cells and cloned into pcDNA3.1(-), pXJ40-Flag or pXJ40-HA respectively, to generate eukaryotic expression plasmids,pcDNA3.1RBM24, pXJ40-Flag-RBM24 and pXJ40-HA-RBM24. A prokaryotic RBM24 expression plasmid pET33b-EK-RBM24 was generated by cloning the coding sequence of RBM24 into pET33b (+). All of the constructs were validated by sequencing.

Prokaryotic expression and purification of recombinant human RBM24

Escherichia coli BL21(DE3) cells were transformed with pET33bEK-RBM24. A positive monocolony was inoculated into $1 \mathrm{~L}$ of $\mathrm{LB}$ medium containing $50 \mu \mathrm{g} / \mathrm{mL}$ of kanamycin and grown at $37^{\circ} \mathrm{C}$ in a shaker until the $A 600$ reached 0.6. Cells were induced with $0.5 \mathrm{mmol} / \mathrm{L}$ isopropyl $\beta$-D-1-thiogalactopyranoside for $4 \mathrm{~h}$ at $37^{\circ} \mathrm{C}$ and were then harvested by centrifugation and resuspended in low imidazole buffer (300 mmol/L NaCl, $50 \mathrm{mmol} / \mathrm{L}$ Tris $(\mathrm{pH} 8.0), 0.02 \%$ $\mathrm{NaN}_{3}, 20 \%$ glycerol, and $10 \mathrm{mmol} / \mathrm{L}$ imidazole) with $0.5 \%$ IGEPAL $®$ and $0.07 \%$ B-ME. Next, the cells were lysed using an ultrasonic homogenizer, and the lysate was clarified by centrifugation and 
filtration through a $0.22 \mu \mathrm{mol} / \mathrm{L}$ syringe filter. The supernatant was loaded onto a column containing $10 \mathrm{~mL}$ Ni-NTA His $• B i n d ®$ resins (Novagen, 70666). After washing sequentially with $10 \mathrm{mmol} / \mathrm{L}$, $50 \mathrm{mmol} / \mathrm{L}$ and $100 \mathrm{mmol} / \mathrm{L}$ imidazole buffer $(20,10$, and 10 column volumes, respectively), the protein was eluted with 1.5 column volumes of $500 \mathrm{mmol} / \mathrm{L}$ imidazole buffer and circulated at $37^{\circ} \mathrm{C}$ for $15 \mathrm{~min}$. After the protein was dialyzed into enterokinase buffer (20 $\mathrm{mmol} / \mathrm{L}$ Tris $(\mathrm{pH} 8.0), 50 \mathrm{mmol} / \mathrm{L} \mathrm{NaCl}, 2 \mathrm{mmol} / \mathrm{L} \mathrm{CaCl}$, and $10 \%$ glycerol), the tag was removed by enterokinase (New England Biolabs, P8070L) digestion followed by Trypsin inhibitor-Agarose (Sigma-Aldrich $®$, T-0637) and His•Bind resin incubation to remove the enterokinase and potentially undigested protein. Tag-free recombinant human RBM24 (rhRBM24) was then dialyzed in RNA binding buffer, concentrated with PEG 20,000, passed through a $0.22 \mu \mathrm{m}$ syringe filter, aliquoted and stored in liquid nitrogen.

\section{Plasmid transfection and RNA interference}

Plasmids and siRNAs were transfected into cells using Lipofectamine 2000 (Invitrogen $^{\mathrm{TM}}, 11668-019$ ), according to the manufacturer's instructions. The following siRNAs were used: AllStars negative control siRNA (siNC, QIAGEN, SI03650318), siHCV (target sequence: 5'-GGUCUCGUAGACCGUGCAC-3') and SiRBM24 (Qiagen, SI03030195). Because transfection of siRBM24 once reduces the RBM24 mRNA level but not the protein level, transfection was performed twice as previously described (Zhu et al., 2014).

\section{RNA extraction and quantitative real-time RT-PCR (qRT-PCR)}

RNA was extracted with TRIzol, and specific RNAs of interest were quantified with a QuantiTect SYBR Green RT-PCR Kit (Qiagen, 204243), following the manufacturer's instructions. The primers for HCV and actin have been described previously (Zhu et al., 2014), and those for RBM24 included RBM24-SybrG-F and RBM24-SybrG$\mathrm{R}$ are listed in Table 1.

Western blot, co-immunoprecipitation (Co-IP) and immunofluorescence analyses

The procedure for Western blotting, co-immunoprecipitation and immunofluorescence was the same as previously described (Xu et al., 2012), noting that $200 \mu \mathrm{g}$ of total protein was used to detect endogenous RBM24. The following antibodies were used: rabbit anti-RBM24 (Abcam ${ }^{\circledR}$, AB94567), rabbit anti-HA (Cell Signaling Technology®, \#3724) and DYKDDDDK (Cell Signaling Technology $®, \# 2368$ ), mouse anti-HA (Sigma-Aldrich $\circledast$, H9658) and mouse anti-FLAG $®$ (Sigma-Aldrich $囚, F 1804)$, and mouse monoclonal antibody (MAb) J2 (Scion, 10010500). For RNase A treatment in the CoIP procedure, $20 \mu \mathrm{g} / \mathrm{mL}$ of RNase A was added to the cell lysate for IP and incubated overnight at $4^{\circ} \mathrm{C}$.

In vitro transcription, in vitro translation and ribosome assembly assay

First, the DNA templates for in vitro transcription were produced by $\mathrm{PCR}$ amplification of pJFH1 with the corresponding T7-tagged forward primers and the reverse primers listed in Table 1. HCV RNA fragments were then generated by in vitro transcription of these DNA templates with a MEGAscript ${ }^{\circledR}$ T7 Transcription Kit (Invitrogen ${ }^{\mathrm{TM}}$, AM1334). Biotin-11-UTP (Invitrogen ${ }^{\mathrm{TM}}$, AM8450) or $\left[\alpha_{-}{ }^{32} \mathrm{P}\right]-\mathrm{UTP}$ (Perkin Elmer, NEG507T250UC) was added to the reaction as required to produce labeled RNA. These RNA fragments were then denatured, digested with TURBO ${ }^{\mathrm{TM}}$ DNase (Ambion $\left.{ }^{\circledR}, \mathrm{AM}^{2} 238\right)$ at $37^{\circ} \mathrm{C}$ for $30 \mathrm{~min}$, purified with TRIzol and dissolved in appropriate buffer.

The template for in vitro translation was generated according to the sequence of pSGR-Luc-JFH1 (Cao et al., 2014) between the EcoRI and Pmel sites. A rabbit reticulocyte lysate (RRL, Promega, L4960)-based translation reaction system was established as previously described (Bai et al., 2013). Briefly, a total of $0.5 \mu \mathrm{g}$ of template RNA and 5 to 50 pmol of rhRBM24 or a non-specific control protein, BSA, were added to $150 \mu \mathrm{L}$ of the reaction system and incubated at $30^{\circ} \mathrm{C}$ for $15 \mathrm{~min}$. The reaction was halted with $1 \times$ Passive Lysis Buffer and luciferase activity was immediately determined with Steady-Glo (Promega, E2520).

For ribosome assembly assay, $1 \mu \mathrm{g}$ of biotin-labeled HCV IRES RNA (J1-360) and 12.5 pmol of rhRBM24 or BSA were added to a ribosome assembly mixture based on RRL. The mixtures were incubated at $30^{\circ} \mathrm{C}$ for $15 \mathrm{~min}$. The reaction was halted, and the mixtures were analyzed with $10 \%-40 \%$ sucrose gradients by ultracentrifugation, as previously described (Filbin et al., 2013). The gradients were fractionated into 22 fractions, and $200 \mu \mathrm{L}$ of each fraction was blotted onto an Amersham Hybond ${ }^{\mathrm{TM}}-\mathrm{N}+$ membrane with a Whatman $\AA$ Minifold $\AA$ I 96 well dot-blot array system. The membrane was crosslinked with a HL-2000 Hybrilinker at 1,200 J, and the blotted biotin-RNA was detected with Streptavidin-HRP (UCytech, CT353) and SuperSignal $\circledast$ West Pico Chemiluminescent Substrate.

\section{RNA immunoprecipitation (RIP)}

RIP was performed as previously described with minor optimizations (Keene et al., 2006). Briefly, Huh7.5.1 cells transfected with pXJ40Flag-RBM24 and infected with $\mathrm{Jc} 1$ were lysed in polysome lysis buffer $(100 \mathrm{mmol} / \mathrm{L} \mathrm{KCl}, 5 \mathrm{mmol} / \mathrm{L} \mathrm{MgCl}, 10 \mathrm{mmol} / \mathrm{L}$ HEPES $(\mathrm{pH}$ 7.0), $0.5 \%$ IGEPAL $®, 1 \mathrm{mmol} / \mathrm{L}$ DTT, 100 units/mL RNasin $囚, 400$ $\mu \mathrm{mol} / \mathrm{L}$ Ribonucleoside Vanadyl Complex (New England Biolabs $®$, S1402S) and complete protease inhibitor cocktail (Roche)) and inverted for $30 \mathrm{~min}$ at $4^{\circ} \mathrm{C}$, and the cell lysate were then centrifuged at $12,000 \times g$ for $15 \mathrm{~min}$ to remove cell debris. The cell lysate containing $800 \mu \mathrm{g}$ total protein was incubated with protein $\mathrm{G}$ beads precoated with mouse anti-FLAG (Sigma-Aldrich, F1804) or a nonspecific control antibody at $30^{\circ} \mathrm{C}$ for $4 \mathrm{~h}$. After washing 5 times with NT-2 buffer (50 mmol/L Tris- $\mathrm{HCl}(\mathrm{pH} 7.5), 150 \mathrm{mmol} / \mathrm{L} \mathrm{NaCl}, 1 \mathrm{mmol} / \mathrm{L}$ $\mathrm{MgCl}_{2}$, and $0.05 \%$ IGEPAL $®$ ), precipitated RNA was extracted with TRIzol for subsequent analysis.

UV crosslinking immunoprecipitation (CLIP)

Total protein was prepared from 293T cells transfected with FlagRBM24 using polysome lysis buffer without RNasin. ${ }^{32} \mathrm{P}$-labeled RNA fragments $(2000 \mathrm{cps})$ were incubated with $100 \mu \mathrm{g}$ total protein for 20 min and then UV crosslinked with a HL-2000 Hybrilinker on ice for $10 \mathrm{~min} .400 \mu \mathrm{L}$ IP buffer containing $30 \mu \mathrm{g}$ RNase A and $30 \mathrm{U}$ RNase ONE ${ }^{\mathrm{TM}}$ were added to each reaction and incubated at $37^{\circ} \mathrm{C}$ for $1 \mathrm{~h}$. The mixtures were incubated with protein $\mathrm{G}$ beads coated 
Table 1. Primers used in the study

\begin{tabular}{|c|c|c|}
\hline & Oligonucleotide & Sequence \\
\hline \multirow[t]{2}{*}{ Primers for RBM24 } & RBM24-SybrG-F & 5'-GGCCAACGTGAACCTGGCATACTT-3' \\
\hline & RBM24-SybrG-R & 5'-GGCAGGTATCCCGAAAGGTCTTTGT-3' \\
\hline \multirow{22}{*}{$\begin{array}{l}\text { Primers for HCV RNA } \\
\text { fragments }\end{array}$} & EcT7- $\Delta 5^{\prime} \mathrm{I}-\mathrm{F}$ & 5'-TGAGGAATTCTAATACGACTCACTATAGACCTGACACTCCGCCATGAATC-3' \\
\hline & J1390-R & 5'-CCCGCTAACGATGTCTATGATGACCTCG-3' \\
\hline & $\Delta 5^{\prime} \mathrm{Il}-\mathrm{F}$ & 5'-CTCCGCCATGAATCACTCCCCCCCCCCTCCCGGGAG-3' \\
\hline & $\Delta 5^{\prime} I I-R$ & 5'-CTCCCGGGAGGGGGGGGGGAGTGATTCATGGCGGAG-3' \\
\hline & EcT7G/FH5-F & 5'-TGAGGAATTCTAATACGACTCACTATAGACCTGCCCCTAATAGGGGCGA-3' \\
\hline & $\Delta 5^{\prime} \mathrm{ll} \mathrm{b}-\mathrm{F}$ & 5'-GTGAGGAACTACTGTCTTCGTCGTACAGCCTCCAGGCCCCCCCC-3' \\
\hline & $\Delta 5^{\prime} \mathrm{llb}-\mathrm{R}$ & 5'-GGGGGGGGCCTGGAGGCTGTACGACGAAGACAGTAGTTCCTCAC-3' \\
\hline & J127-T7-F & 5'-TAATACGACTCACTATAGGGACTCCCGGGAGAGCCATAGTGGTCTG-3' \\
\hline & J149-R & 5'-CAGACCACTATGGCTCTCCCGGG-3' \\
\hline & J336-T7-F & 5'-TAATACGACTCACTATAGGGACTGCACCATGAGCACAAATCCTAAACC-3' \\
\hline & J360-R & 5'-GGTTTAGGATTTGTGCTCATGGTGC-3' \\
\hline & J530-T7-F & 5'-TAATACGACTCACTATAGGGACTCCCATCCCCAAAGATCGGCGCTCC-3' \\
\hline & J553-R & 5'-GGAGCGCCGATCTTTGGGGATGGG-3' \\
\hline & J875-T7-F & 5'-TAATACGACTCACTATAGGGACTGGCCCTGTTGTCCTGCATCAC-3' \\
\hline & J897-R & 5'-GTGATGCAGGACAACAGGGCCAG-3' \\
\hline & J1484-R & 5'-CCACCCCAGCGGCCAGCAGAAGG-3' \\
\hline & J9166-T7-F & 5'-TAATACGACTCACTATAGGGACTGAAGAGTCGGGCTCGCGCAGTCAGG-3' \\
\hline & J9440-T7-F & 5'-TAATACGACTCACTATAGGGACTAGAGCGGCACACACTAGGTACACTCC-3' \\
\hline & J9463-R & 5'-GTGTACCTAGTGTGTGCCGCTC-3' \\
\hline & J9578-T7-F & 5'-TAATACGACTCACTATAGGGACTTGGTGGCTCCATCTTAGCCCTAG-3' \\
\hline & J9578-R & 5'-GAAAGAAAGTAGAATAAGATGAGAAGGG-3' \\
\hline & J9678-R & 5'-ACATGATCTGCAGAGAGACCAGTTACGGC-3' \\
\hline \multirow[t]{4}{*}{ Primers for RPA probes } & J5025-T7-F & 5'-TAATACGACTCACTATAGGGACTGGGAGGCAGTTTTCACCGGCC-3' \\
\hline & J5025-F & 5'-GGGAGGCAGTTTTTCACCGGCC-3' \\
\hline & J5350-T7-R & 5'-TAATACGACTCACTATAGGGACTGACTCCTCCAGCTAGGACCCACGTGC-3' \\
\hline & J5350-R & 5'-GACTCCTCCAGCTAGGACCCACGTGC-3' \\
\hline
\end{tabular}

The T7 promoter sequence was marked as italic, and the restriction enzyme sites are shown by underline.

with the indicated antibody at $30^{\circ} \mathrm{C}$ for $4 \mathrm{~h}$. The beads were then washed 5 times with IP buffer, incubated at $95^{\circ} \mathrm{C}$ for 10 min with $2 \times$ Laemmli buffer and subjected to SDS-PAGE. The gel was dried with a Model 583 gel dryer (Bio-Rad) and autoradiographed on a phosphor screen (Perkin Elmer, 7001722) for 1-7 days. Signal was collected with a Cyclone ${ }^{\circledR}$ Plus and analyzed with OptiQuant ${ }^{\mathrm{TM}}$.

RNase protection assay (RPA)

${ }^{32} \mathrm{P}$-labeled probes for $\mathrm{HCV}$ positive-strand and negative-strand detection were prepared by in vitro transcription and dissolved in $1 \times$ RPA Buffer (40 mmol/L PIPES (pH 6.4), 1 mmol/L EDTA (pH 8.0), $400 \mathrm{mmol} / \mathrm{L} \mathrm{NaCl}$, and $80 \%$ formamide). Standard RPA was performed to detect positive-strand HCV RNA (Guan et al., 2011). Total RNA was incubated with ${ }^{32} \mathrm{P}$-labeled probes and hybridized in hybridization buffer by incubation overnight at $51^{\circ} \mathrm{C}$ after denaturation at $95^{\circ} \mathrm{C}$ for $15 \mathrm{~min}$. RNase digestion was performed with $300 \mu \mathrm{L}$ of RNA digestion mix $(500 \mathrm{mmol} / \mathrm{L} \mathrm{NaCl}, 10 \mathrm{mmol} / \mathrm{L}$ Tris $(\mathrm{pH} 7.5)$, $5 \mathrm{mmol} / \mathrm{L}$ EDTA, $350 \mathrm{U} / \mathrm{mL}$ RNase T1, and $4.5 \mu \mathrm{g} / \mathrm{mL}$ RNase A) at $30^{\circ} \mathrm{C}$ for $1 \mathrm{~h}$. Reactions were stopped by the addition of $50 \mu \mathrm{g}$ of proteinase $\mathrm{K}$ and $20 \mu \mathrm{L} 10 \% \mathrm{SDS}$. The samples were precipitated with ethanol and glycogen (Thermo Scientific, R0551) and analyzed by $6 \%$ urea-PAGE. The gel was dried and autoradiographed as described above.

\section{Streptavidin pulldown}

The biotin-RNA fragments of interest dissolved in RNA folding buffer (100 mmol/L KCl, $20 \mathrm{mmol} / \mathrm{L}$ HEPES (pH 7.6), and $5 \mathrm{mmol} / \mathrm{L} \mathrm{MgCl}_{2}$ ) were folded by incubation at $70^{\circ} \mathrm{C}$ for $2 \mathrm{~min}$ and cooled at RT. The 
total protein $(400 \mu \mathrm{g})$ of interest was incubated with $50 \mathrm{pmol}$ of the indicated folded biotin-RNA fragments, $40 \mathrm{U}$ of RNasin and $50 \mu \mathrm{g}$ of yeast tRNA (Ambion, AM7119) at $30^{\circ} \mathrm{C}$ for $30 \mathrm{~min}$. Dynabeads M-280 Streptavidin (Invitrogen ${ }^{\mathrm{TM}}, 11205 \mathrm{D}$ ) were resuspended with $400 \mu \mathrm{L}$ of RNA binding buffer after being sequentially washed with $1 \mathrm{~mL}$ each of solution $A(0.1 \mathrm{~mol} / \mathrm{L} \mathrm{NaOH}$ and $0.05 \mathrm{~mol} / \mathrm{L} \mathrm{NaCl})$, solution $B(0.1 \mathrm{~mol} / \mathrm{L} \mathrm{NaCl})$ and RNA binding buffer $(100 \mathrm{mmol} / \mathrm{L}$ $\mathrm{KCl}, 20 \mathrm{mmol} / \mathrm{L}$ HEPES (pH 7.6), $5 \mathrm{mmol} / \mathrm{L} \mathrm{MgCl}_{2}, 10 \%$ glycerol, $1 \mathrm{mmol} / \mathrm{L}$ DTT, $0.1 \%$ IGEPAL $\AA$, and $400 \mu \mathrm{mol} / \mathrm{L}$ RVC), with two washes in each solution. The aforementioned motioned protein-RNA mixtures were then added to the beads and incubated at $30^{\circ} \mathrm{C}$ for $2 \mathrm{~h}$. The beads were washed 5 times with RNA binding buffer by magnetic separation, incubated at $95^{\circ} \mathrm{C}$ for $10 \mathrm{~min}$ with $2 \times$ Laemmli buffer, and subjected to Western blotting.

\section{5'-, 3'-UTR co-precipitation assay}

5'-, 3'-UTR co-precipitation assay was performed as previously described with minor optimizations (Wang et al., 2011). Briefly, biotin-RNA was incubated with $25 \mu \mathrm{L}$ streptavidin beads at $30^{\circ} \mathrm{C}$ for 30 min. ${ }^{32} \mathrm{P}$-labeled RNA probes were incubated with BSA or rhRBM24 in the presence of $10 \mu \mathrm{g}$ tRNA (and cold competitor RNA for the experiments described in Fig. $5 \mathrm{C}$ ) at $30^{\circ} \mathrm{C}$ for 30 min in RNA binding buffer. The mixtures were then incubated with RNA-coated streptavidin beads at $30^{\circ} \mathrm{C}$ for $2 \mathrm{~h}$. The beads were collected, washed, and incubated in Gel Loading Buffer II (Ambion ${ }^{2}, A M 8546 \mathrm{G}$ ) at $95^{\circ} \mathrm{C}$ for $10 \mathrm{~min}$. The precipitated RNA was then analyzed with a $6 \%$ ureaPAGE gel and autoradiographed

\section{Statistical analysis}

The data were analyzed using the two-tailed unpaired $t$-test. Statistical significance was set at a ${ }^{*}(P<0.05)$ or ${ }^{* *}(P<0.01)$.

\section{ACKNOWLEDGEMENTS}

We are grateful to Mr. Jumin Xie, Huanzhou Xu and Prof. Wuxiang Guan for their technical support for streptavidin pulldown, CLIP assays and RPA, and to Dr. Rui Jin and Prof. Peng Gong for their technical support for prokaryotic expression and purification of RBM24. This work was supported by grants from the National Basic Research Priorities Program of China (2013CB911100) and National Natural Science Foundation of China (Grant Nos. 31621061 and 81461130019). Rongjuan Pei was supported by the National Natural Science Foundation of China (81672021).

\section{ABBREVIATIONS}

AA, amino acid; CLIP, UV cross-linking and immunoprecipitation; Co-IP, co-immunoprecipitation; EMCV, encephalomyocarditis virus; FFU, focus-forming unit; $\mathrm{HBV}$, hepatitis $B$ virus; $\mathrm{HCV}$, hepatitis $\mathrm{C}$ virus; IRES, internal ribosome entry sit; JEV, Japanese encephalitis virus; NSAP1, NS1-associated protein 1; PCBP2, poly(rC)-binding protein 2; PTB, polypyrimidine tract binding protein; qRT-PCR, quantitative real-time RT-PCR; RRL, rabbit reticulocyte lysate; RBM24, RNA binding motif protein 24; RIP, RNA immunoprecipitation; RPA, RNase protection assay; RRM, RNA recognition motif; UTR, untranslated region.

\section{COMPLIANCE WITH ETHICS GUIDELINES}

Huang Cao, Kaitao Zhao, Yongxuan Yao, Jing Guo, Xiaoxiao Gao, Qi Yang, Min Guo, Wandi Zhu, Yun Wang, Chunchen Wu, Jizheng Chen, Yuan Zhou, Xue Hu, Mengji Lu, Xinwen Chen and Rongjuan Pei declare that they have no conflict of interest.

\section{OPEN ACCESS}

This article is distributed under the terms of the Creative Commons Attribution 4.0 International License (http://creativecommons.org/ licenses/by/4.0/), which permits unrestricted use, distribution, and reproduction in any medium, provided you give appropriate credit to the original author(s) and the source, provide a link to the Creative Commons license, and indicate if changes were made.

\section{REFERENCES}

Ali N, Pruijn GJ, Kenan DJ, Keene JD, Siddiqui A (2000) Human La antigen is required for the hepatitis $C$ virus internal ribosome entry site-mediated translation. J Biol Chem 275:27531-27540

Astier-Gin T, Bellecave P, Litvak S, Ventura M (2005) Template requirements and binding of hepatitis $C$ virus NS5B polymerase during in vitro RNA synthesis from the 3'-end of virus minusstrand RNA. FEBS J 272:3872-3886

Bai Y, Zhou K, Doudna JA (2013) Hepatitis C virus 3'UTR regulates viral translation through direct interactions with the host translation machinery. Nucleic Acids Res 41:7861-7874

Bhat P, Shwetha S, Sharma DK, Joseph AP, Srinivasan N, Das S (2015) The beta hairpin structure within ribosomal protein S5 mediates interplay between domains II and IV and regulates HCV IRES function. Nucleic Acids Res 43:2888-2901

Boehringer D, Thermann R, Ostareck-Lederer A, Lewis JD, Stark H (2005) Structure of the hepatitis $C$ virus IRES bound to the human $80 \mathrm{~S}$ ribosome: remodeling of the HCV IRES. Structure 13:1695-1706

Cao H, Zhu W, Han Q, Pei R, Chen X (2014) Construction of a chimeric hepatitis $C$ virus replicon based on a strain isolated from a chronic hepatitis C patient. Virol Sin 29:61-70

Chang KS, Luo G (2006) The polypyrimidine tract-binding protein (PTB) is required for efficient replication of hepatitis $\mathrm{C}$ virus $(\mathrm{HCV})$ RNA. Virus Res 115:1-8

Cheng JC, Chang MF, Chang SC (1999) Specific interaction between the hepatitis C virus NS5B RNA polymerase and the 3' end of the viral RNA. J Virol 73:7044-7049

Filbin ME, Kieft JS (2011) HCV IRES domain Ilb affects the configuration of coding RNA in the $40 \mathrm{~S}$ subunit's decoding groove. RNA 17:1258-1273

Filbin ME, Vollmar BS, Shi D, Gonen T, Kieft JS (2013) HCV IRES manipulates the ribosome to promote the switch from translation initiation to elongation. Nat Struct Mol Biol 20:150-158

Fontanes V, Raychaudhuri S, Dasgupta A (2009) A cell-permeable peptide inhibits hepatitis $C$ virus replication by sequestering IRES transacting factors. Virology 394:82-90 
Friebe P, Boudet J, Simorre JP, Bartenschlager R (2005) Kissingloop interaction in the 3 ' end of the hepatitis $C$ virus genome essential for RNA replication. J Virol 79:380-392

Guan W, Cheng F, Huang Q, Kleiboeker S, Qu J (2011) Inclusion of the central exon of parvovirus B19 precursor mRNA is determined by multiple splicing enhancers in both the exon and the downstream intron. J Virol 85:2463-2468

Guo M, Pei R, Yang Q, Cao H, Wang Y, Wu C, Chen J, Zhou Y, Hu X, Lu M et al (2014) Phosphatidylserine-specific phospholipase A1 is involved in hepatitis C Virus Assembly through NS2 complex formation. J Virol 89:2367-2377

Heise T, Guidotti LG, Chisari FV (1999) La autoantigen specifically recognizes a predicted stem-loop in hepatitis B virus RNA. J Virol 73:5767-5776

Horke S, Reumann K, Rang A, Heise T (2002) Molecular characterization of the human La protein.hepatitis B virus RNA.B interaction in vitro. J Biol Chem 277:34949-34958

Ito T, Lai MM (1997) Determination of the secondary structure of and cellular protein binding to the 3'-untranslated region of the hepatitis C virus RNA genome. J Virol 71:8698-8706

Jin D, Hidaka K, Shirai M, Morisaki T (2010) RNA-binding motif protein 24 regulates myogenin expression and promotes myogenic differentiation. Genes Cells 15:1158-1167

Jones DM, Atoom AM, Zhang X, Kottilil S, Russell RS (2011) A genetic interaction between the core and NS3 proteins of hepatitis $C$ virus is essential for production of infectious virus. J Virol 85:12351-12361

Kaminski A, Jackson RJ (1998) The polypyrimidine tract binding protein (PTB) requirement for internal initiation of translation of cardiovirus RNAs is conditional rather than absolute. RNA 4:626638

Keene JD, Komisarow JM, Friedersdorf MB (2006) RIP-Chip: the isolation and identification of mRNAs, microRNAs and protein components of ribonucleoprotein complexes from cell extracts. Nat Protoc 1:302-307

Kim SM, Jeong YS (2006) Polypyrimidine tract-binding protein interacts with the 3' stem-loop region of Japanese encephalitis virus negative-strand RNA. Virus Res 115:131-140

Kim YK, Kim CS, Lee SH, Jang SK (2002) Domains I and II in the 5' nontranslated region of the HCV genome are required for RNA replication. Biochem Biophys Res Commun 290:105-112

Kim JH, Paek KY, Ha SH, Cho S, Choi K, Kim CS, Ryu SH, Jang SK (2004) A cellular RNA-binding protein enhances internal ribosomal entry site-dependent translation through an interaction downstream of the hepatitis $\mathrm{C}$ virus polyprotein initiation codon. Mol Cell Biol 24:7878-7890

Kumar A, Ray U, Das S (2013) Human La protein interaction with GCAC near the initiator AUG enhances hepatitis C Virus RNA replication by promoting linkage between 5' and 3' untranslated regions. J Virol 87:6713-6726

Li D, Takyar ST, Lott WB, Gowans EJ (2003) Amino acids 1-20 of the hepatitis $\mathrm{C}$ virus $(\mathrm{HCV})$ core protein specifically inhibit $\mathrm{HCV}$ IRES-dependent translation in HepG2 cells, and inhibit both HCV IRES- and cap-dependent translation in $\mathrm{HuH} 7$ and $\mathrm{CV}-1$ cells. J Gen Virol 84:815-825

Liu HM, Aizaki H, Choi KS, Machida K, Ou JJ, Lai MM (2009) SYNCRIP (synaptotagmin-binding, cytoplasmic RNA-interacting protein) is a host factor involved in hepatitis $C$ virus RNA replication. Virology 386:249-256

Locker N, Easton LE, Lukavsky PJ (2007) HCV and CSFV IRES domain II mediate elF2 release during $80 \mathrm{~S}$ ribosome assembly. EMBO J 26:795-805

Lukavsky PJ (2009) Structure and function of HCV IRES domains. Virus Res 139:166-171

Mahias K, Ahmed-El-Sayed N, Masante C, Bitard J, Staedel C, Darfeuille F, Ventura M, Astier-Gin T (2010) Identification of a structural element of the hepatitis $C$ virus minus strand RNA involved in the initiation of RNA synthesis. Nucleic Acids Res 38:4079-4091

Malygin AA, Kossinova OA, Shatsky IN, Karpova GG (2013) HCV IRES interacts with the 18S rRNA to activate the 40 S ribosome for subsequent steps of translation initiation. Nucleic Acids Res 41:8706-8714

Measey TJ, Smith KB, Decatur SM, Zhao L, Yang G, SchweitzerStenner R (2009) Self-aggregation of a polyalanine octamer promoted by its C-terminal tyrosine and probed by a strongly enhanced vibrational circular dichroism signal. J Am Chem Soc 131:18218-18219

Miyamoto S, Hidaka K, Jin D, Morisaki T (2009) RNA-binding proteins $\mathrm{Rbm} 38$ and $\mathrm{Rbm} 24$ regulate myogenic differentiation via p21-dependent and -independent regulatory pathways. Genes Cells 14:1241-1252

Park SM, Paek KY, Hong KY, Jang CJ, Cho S, Park JH, Kim JH, Jan E, Jang SK (2011) Translation-competent 48S complex formation on HCV IRES requires the RNA-binding protein NSAP1. Nucleic Acids Res 39:7791-7802

Pietschmann T, Kaul A, Koutsoudakis G, Shavinskaya A, Kallis S, Steinmann E, Abid K, Negro F, Dreux M, Cosset FL et al (2006) Construction and characterization of infectious intragenotypic and intergenotypic hepatitis $C$ virus chimeras. Proc Natl Acad Sci USA 103:7408-7413

Poon KL, Tan KT, Wei YY, Ng CP, Colman A, Korzh V, Xu XQ (2012) RNA-binding protein RBM24 is required for sarcomere assembly and heart contractility. Cardiovasc Res 94:418-427

Ranjith-Kumar CT, Kao CC (2006) Biochemical activities of the HCV NS5B RNA-dependent RNA polymerase. Hepatitis C viruses: genomes and molecular biology. Chapter 10. Horizon Bioscience, Norfolk, UK

Ray U, Das S (2011) Interplay between NS3 protease and human La protein regulates translation-replication switch of Hepatitis C virus. Sci Rep 1:1

Reigadas S, Ventura M, Sarih-Cottin L, Castroviejo M, Litvak S, Astier-Gin T (2001) HCV RNA-dependent RNA polymerase replicates in vitro the 3 ' terminal region of the minus-strand viral RNA more efficiently than the 3' terminal region of the plus RNA. Eur J Biochem 268:5857-5867

Romero-Lopez C, Berzal-Herranz A (2009) A long-range RNA-RNA interaction between the 5' and 3' ends of the HCV genome. RNA 15:1740-1752

Romero-Lopez C, Berzal-Herranz A (2012) The functional RNA domain 5BSL3.2 within the NS5B coding sequence influences hepatitis $C$ virus IRES-mediated translation. Cell Mol Life Sci 69:103-113 
Schuster C, Isel C, Imbert I, Ehresmann C, Marquet R, Kieny MP (2002) Secondary structure of the 3 ' terminus of hepatitis $C$ virus minus-strand RNA. J Virol 76:8058-8068

Shetty S, Kim S, Shimakami T, Lemon SM, Mihailescu MR (2010) Hepatitis C virus genomic RNA dimerization is mediated via a kissing complex intermediate. RNA 16:913-925

Shetty S, Stefanovic S, Mihailescu MR (2013) Hepatitis C virus RNA: molecular switches mediated by long-range RNA-RNA interactions? Nucleic Acids Res 41:2526-2540

Shi ST, Lai MMC (2006) HCV 5' and 3' UTR: when translation meets replication. Hepatitis $C$ Viruses: genomes and molecular biology. Chapter 2. Horizon Bioscience, Norfolk, UK

Shimoike T, Mimori S, Tani H, Matsuura Y, Miyamura T (1999) Interaction of hepatitis $C$ virus core protein with viral sense RNA and suppression of its translation. J Virol 73:9718-9725

Shimoike T, Koyama C, Murakami K, Suzuki R, Matsuura Y, Miyamura T, Suzuki T (2006) Down-regulation of the internal ribosome entry site (IRES)-mediated translation of the hepatitis $C$ virus: critical role of binding of the stem-loop IIId domain of IRES and the viral core protein. Virology 345:434-445

Shwetha S, Kumar A, Mullick R, Vasudevan D, Mukherjee N, Das S (2015) HuR displaces PTB to facilitate La binding to the 3' UTR and enhances HCV replication. J Virol 89:11356-11371

Spahn CM, Kieft JS, Grassucci RA, Penczek PA, Zhou K, Doudna JA, Frank J (2001) Hepatitis C virus IRES RNA-induced changes in the conformation of the $40 \mathrm{~s}$ ribosomal subunit. Science 291:1959-1962

Spangberg K, Schwartz S (1999) Poly(C)-binding protein interacts with the hepatitis C virus 5' untranslated region. J Gen Virol $80(\mathrm{Pt}$ 6):1371-1376

Sun C, Querol-Audi J, Mortimer SA, Arias-Palomo E, Doudna JA, Nogales E, Cate JH (2013) Two RNA-binding motifs in elF3 direct HCV IRES-dependent translation. Nucleic Acids Res 41:75127521

Tanaka Y, Shimoike T, Ishii K, Suzuki R, Suzuki T, Ushijima H, Matsuura Y, Miyamura T (2000) Selective binding of hepatitis $C$ virus core protein to synthetic oligonucleotides corresponding to the 5' untranslated region of the viral genome. Virology 270:229236
Tsukiyama-Kohara K, lizuka N, Kohara M, Nomoto A (1992) Internal ribosome entry site within hepatitis C virus RNA. J Virol 66:14761483

Vashist S, Anantpadma M, Sharma H, Vrati S (2009) La protein binds the predicted loop structures in the 3' non-coding region of Japanese encephalitis virus genome: role in virus replication. J Gen Virol 90:1343-1352

Vashist S, Bhullar D, Vrati S (2011) La protein can simultaneously bind to both $3^{\prime}$ - and 5 '-noncoding regions of Japanese encephalitis virus genome. DNA Cell Biol 30:339-346

Wang L, Jeng KS, Lai MM (2011) Poly(C)-binding protein 2 interacts with sequences required for viral replication in the hepatitis $C$ virus (HCV) 5' untranslated region and directs HCV RNA replication through circularizing the viral genome. J Virol 85:7954-7964

Wood J, Frederickson RM, Fields S, Patel AH (2001) Hepatitis C virus $3^{\prime} X$ region interacts with human ribosomal proteins. J Virol 75:1348-1358

Xu S, Pei R, Guo M, Han Q, Lai J, Wang Y, Wu C, Zhou Y, Lu M, Chen $X$ (2012) Cytosolic phospholipase $A 2$ gamma is involved in hepatitis C virus replication and assembly. J Virol 86:1302513037

Xu E, Zhang J, Zhang M, Jiang Y, Cho SJ, Chen X (2014) RNAbinding protein RBM24 regulates p63 expression via mRNA stability. Mol Cancer Res 12:359-369

Yang J, Hung LH, Licht T, Kostin S, Looso M, Khrameeva E, Bindereif A, Schneider A, Braun T (2014) RBM24 is a major regulator of muscle-specific alternative splicing. Dev Cell 31:8799

Zang WQ, Li B, Huang PY, Lai MM, Yen TS (2001) Role of polypyrimidine tract binding protein in the function of the hepatitis B virus posttranscriptional regulatory element. J Virol 75:1077910786

Zhu W, Pei R, Jin R, Hu X, Zhou Y, Wang Y, Wu C, Lu M, Chen X (2014) Nuclear receptor 4 group A member 1 determines hepatitis $C$ virus entry efficiency through the regulation of cellular receptor and apolipoprotein E expression. J Gen Virol 95:15101521 